\title{
CONHECENDO O CAMPO SOBRE FOOD EXPERIENCE: UMA REVISÃO BIBLIOMÉTRICA DOS ÚLTIMOS 20 ANOS NA BASE WEB OF SCIENCE
}

Laura de Oliveira Cardoso

UFMG/Graduanda em Administração cardosolaura18@gmail.com

Frederico Leocádio Ferreira

UFMG/Doutorando em Administração fredericoleocadio@gmail.com

Juliana Maria Magalhães Christino UFMG/Professora Adjunta do Departamento de Ciências Administrativas da FACE julianam.prof@gmail.com

Ana Luíza Silva Noronha UFMG/Graduanda em Administração analuiza3422@gmail.com

\section{Resumo}

Objetivo do estudo: O objetivo desta pesquisa é realizar uma revisão bibliométrica sobre "Food Experience" visando a um mapeamento da área, até então pouco explorada e em um estágio embrionário no Brasil.

Metodologia/Abordagem: O estudo teve como intervalo de tempo um período de vinte anos, de 1999 a 2019. A busca na base Web of Science resultou em 187 artigos, e não houve nenhuma filtragem. Por fim, os resultados foram extraídos da base de dados e baixados para o CiteSpace.

Originalidade/Relevância: $\mathrm{O}$ trabalho tem sua originalidade ao fornecer um panorama de pesquisa, que pode incentivar estudos futuros sobre Food Experience, guiando-os sobre as principais tendências sobre o conceito. Para além, o termo Food Experience ainda não possui uma definição clara e se insere em um campo de estudo disperso, cujo mapeamento bibliométrico ajudaria a sua estruturação.

Principais resultados: Percebe-se um aumento do volume de publicações nos últimos anos. Os principais autores que trabalham com o tema foram mapeados, e os estudos concentram-se nas áreas sobre qualidade e impacto do serviço, bem como satisfação do consumidor. A indexação ocorre principalmente nas áreas de administração, ciências sociais e turismo.

Contribuições teórico-metodológicas: No ano de 2018, ocorreu um aumento gradativo de publicações acerca de Food Experience, o que indica uma contemporaneidade do tema. Sugere-se que novas pesquisas bibliométricas sejam realizadas com a base SCOPUS, bem como uma revisão sistemática para entender a fundo o conceito, as aplicações e as agendas de pesquisa dentro de Food Experience.

Palavras-chave: Food experience. Experiência gastronômica. Revisão bibliométrica.

\section{Cite como}

American Psychological Association (APA)

Cardoso, L. O., Ferreira, F. L., Christino, J. M. M., \& Noronha, A. L. S. (2022, jan./abr.). Conhecendo o campo sobre food experience: uma revisão bibliométrica dos últimos 20 anos na base web of Science. PODIUM Sport, Leisure and Tourism Review, São Paulo, 11(1), 89-120. https://doi.org/10.5585/podium.v11i1.19547. 


\section{KNOWING THE FIELD ABOUT FOOD EXPERIENCE: A BIBLIOMETRIC REVIEW OF THE PAST 20 YEARS ON THE WEB OF SCIENCE DATABASE}

Abstract

Objective of the study: The purpose of this research is to carry out a bibliometric review on "Food Experience". The study aims to develop area mapping, so far little explored and in an embryonic stage in Brazil.

Methodology/Approach:The time span of the study was a period of twenty years, from 1999 to 2019 . The search in the Web of Science database resulted in 187 articles, and there was no filtering. Finally, the results were extracted from the database and downloaded to CiteSpace.

Originality / Relevance: The work has its originality in providing a research overview, which can encourage future studies on food experience, guiding them on the main trends regarding the concept. Furthermore, the term food experience still does not have a clear definition and is inserted in a dispersed field of study. Therefore, bibliometric mapping would help its structuring.

Main results: There has been noticed an increase in the volume of publications in recent years. The main authors who work with the theme were mapped. Food experience studies focus on the areas of quality and impact of the service, as well as consumer satisfaction. Indexing takes place mainly in the areas of business, social sciences and tourism.

Theoretical/methodological contributions: In 2018, there was a gradual increase in articles about food experience, which indicates that the topic is contemporary. It is suggested that new bibliometric research be carried out with the SCOPUS base. Furthermore, a systematic review could be developed to fully understand the concept, applications and research agendas within food experience.

Keywords: Food experience. Gastronomic experience. Bibliometric review.

\section{CONOCIENDO EL CAMPO SOBRE LA EXPERIENCIA ALIMENTARIA: Una revisión bibliométrica de los últimos 20 años en la base de datos de Web of Science.}

\section{Resumen}

Objetivo del estúdio: El objetivo de esta investigación es realizar una revisión bibliométrica sobre la "experiencia alimentaria" con el objetivo de hacer un mapeo de la zona, hasta entonces poco explorada y se encuentra en etapa embrionaria en Brasil.

Metodología/Enfoque: El estudio abarcó un período de veinte años, de 1999 a 2019. La búsqueda en la base de datos de Web of Science dio como resultado 187 artículos y no hubo filtrado. Finalmente, los resultados se extrajeron de la base de datos y se descargaron a CiteSpace.

Originalidad/Relevancia: El trabajo tiene su originalidad al ofrecer un panorama de la investigación, que puede incentivar futuros estudios sobre la experiencia alimentaria, orientándolos sobre las principales tendencias en torno al concepto. Además, el término experiencia alimentaria aún no tiene una definición clara y se inserta en un campo de estudio disperso, cuyo mapeo bibliométrico ayudaría a su estructuración.

Resultados principales: Hay un aumento en el volumen de publicaciones en los últimos años. Se han mapeado los principales autores que trabajan con el tema, y los estudios se centran en las áreas de calidad e impacto del servicio, así como en la satisfacción del consumidor. La indexación se produce principalmente en las áreas de administración, ciencias sociales y turismo.

Contribuciones teóricas/metodológicas: En 2018 hubo un aumento paulatino de publicaciones sobre la experiencia gastronómica, lo que indica un tema contemporáneo. Se sugiere que se realicen nuevas investigaciones bibliométricas con la base SCOPUS, así como una revisión sistemática para comprender a fondo el concepto, las aplicaciones y las agendas de investigación dentro de la Experiencia Alimentaria.

Palabras clave: Food Experience. Experiencia gastronómica. Revisión bibliométrica. 
Cardoso, L. O., Ferreira, F. L., Christino, J. M. M., \& Noronha, A. L. S. (2022, jan./abr.). Conhecendo o campo sobre food experience: uma revisão bibliométrica dos últimos 20 anos na base web of Science

\section{Introdução}

A alimentação na contemporaneidade vai além da mera ingestão de nutrientes e constitui um fenômeno complexo que reflete os aspectos culturais, econômicos e tecnológicos de uma comunidade (Gândara, Gimenes, \& Mascarenhas, 2009). Enquanto pertencente ao conjunto de necessidades básicas do ser humano para sua sobrevivência, desde crianças, indivíduos são familiarizados aos hábitos alimentares, que podem refletir suas crenças e costumes (Mintz, 2001). Alimentar-se pode significar uma simbologia para um consumidor, e essa simbologia pode ser aguçada quando o estabelecimento comercial consegue retratar valores culturais e sociais de cada indivíduo (Warde, 2018).

O meio gastronômico pode trazer como uma de suas principais ofertas, a experiência em entreter - uma experiência diferente da rotina normal (Gregorash, 2017). Diversos fatores influenciam a escolha do consumidor quando eles saem para comer, como: o prazer de estar junto, o prazer de se alimentar, bem como o desejo de seguir um posicionamento ideológico e estilo de vida, em que "a formação social do paladar vincula-se também a representação simbólica atribuída a bares, restaurantes e similares, justamente porque os consumidores também constroem suas preferências em relação à marca dos estabelecimentos" (Gândara, Gimenes, \& Mascarenhas, 2009). Esse significado simbólico está diretamente ligado ao "Food Experience", um termo em inglês que pode ser traduzido como experiência gastronômica.

O presente estudo adota como definição de "Food Experience" a experiência gastronômica total, para além da comida em si, considerando também outros fatores como o interior e a decoração do restaurante (Longart, Wickens, \& Bakir, 2018); as interações sociais entre clientes, e entre clientes e funcionários (Hansen, Jensen, \& Gustaffon, 2005; McNeill \& Mather, 2016); e o ambiente, que se refere à formação da atmosfera do restaurante, a partir da música, iluminação e da configuração do espaço, por exemplo (Kotler, 1973; Wu \& Liang, 2009). A experiência gastronômica leva em conta o tipo de clientela: por exemplo, para consumidores turistas e não locais, o objetivo seria compartilhar a cultura tradicional local (Sthapit, 2017). Essa comida local é fundamental para a experiência turística (Björk \& Kauppinen-Räisänen, 2016). Portanto, os meios gastronômicos buscam criar memórias que oferecem momentos de prazer e felicidade das experiências alimentares podendo afetar o comportamento pós-viagem, como intenções de revisitar e compartilhar as vivências por meio de registros fotográficos, posts na internet e contação de histórias (Sthapit, 2018; Wang, Kirillova, \& Lehto, 2017). 
Já em situações em que o foco são moradores locais, o conceito de "Food Experience" é utilizado como uma maneira de estabelecer diferencial e/ou autenticidade para o restaurante, a partir das mais variadas temáticas que podem ser definidas para o meio gastronômico (Gregorash, 2017). Criar experiências agradáveis e únicas são formas de intensificar as emoções positivas (Jang \& Namkung, 2009), de conquistar a lealdade do consumidor (Yoon, Thompson, \& Parsa, 2009; Peng \& Chen, 2015) e aumentar as chances de compartilhar a experiência com outras pessoas (Kim \& Jang, 2018).

No contexto brasileiro, micro e macroempreendedores se dedicam a favorecer experiências gastronômicas que satisfaçam o consumidor e que gerem diferenciação ao seu negócio (Sebrae, 2018), utilizando, para este fim, inovações por meio dos cinco sentidos: (i) paladar e olfato, tal qual o restaurante Demattê, em Jacaraípe-ES que possui produção integralmente artesanal e preza pelo pequeno agricultor enquanto fornecedor, valorizando o conceito de comfort food - ou seja, transmitindo conforto ao consumidor por meio das memórias sensoriais e afetivas, utilizando ingredientes locais e culturais; (ii) da visão, como o restaurante Soeta em Vitória, que tem o menu voltado para a culinária internacional e traz como diferencial a apresentação dos pratos de forma criativa, divertida e original (SEBRAE, 2017); (iii) pelo tato, como as experiências fornecidas pela chef Helen Puterman, denominados "jantar às cegas" no qual os clientes utilizam vendas sobre os olhos com o objetivo de estimular as percepções sensoriais (Globo, 2016); e (iv) pela audição, como é caso do bistrô Birosca s2, em Belo Horizonte, que além de apresentar uma decoração retrô e sofisticada, é conhecido por suas noites de jazz, choro e samba tocadas no piano ao vivo em um ambiente descontraído (Jornal da Cidade, 2018).

Apesar de sua importância mercadológica, os estudos sobre o tema no Brasil ainda encontram-se em estágio embrionário, havendo cinco publicações brasileiras indexadas na Scielo - base de periódicos especializados em artigos brasileiros; dois artigos indexados na base Web of Science; e setenta publicações com essa temática na Google Scholars — com a ressalva de que, nessa base, as publicações englobam journals sem qualis, dissertações, teses, trabalhos de conclusão de curso e trabalhos publicados em anais de congresso. Uma revisão bibliométrica poderia servir de incentivo para que novos pesquisadores se empenhem em estudar sobre o termo "Food Experience", formulando questões de pesquisa com base no campo intelectual já existente e suas lacunas. Assim, torna-se importante, para entender melhor o conceito acerca de "Food Experience", mapear seu campo de estudo, trazendo tendências de 
Cardoso, L. O., Ferreira, F. L., Christino, J. M. M., \& Noronha, A. L. S. (2022, jan./abr.). Conhecendo o campo sobre food experience: uma revisão bibliométrica dos últimos 20 anos na base web of Science

estudo - um panorama que pode guiar novas pesquisas sobre o tema. Não foi encontrada outra revisão bibliométrica sobre o tema.

O objetivo desta pesquisa é o mapeamento bibliométrico do campo de estudos do "Food Experience", por meio da ferramenta Citespace. Especificamente, o trabalho visa mapear a produção (volume) de publicações sobre o tema nos últimos anos, bem como quais são os autores mais produtivos, e entender, por meio das referências coletadas, quais países trabalham com o tema, com quais palavras-chaves os trabalhos estão indexados, quais journals publicam sobre o tópico, assim como entender quais são os campos mais proeminentes no estudo — por meio de clusters. A revisão bibliométrica trabalha com as referências bibliográficas dos artigos indexados na Web of Science (base escolhida para a análise), portanto, dá um panorama sobre o campo de Food Experience, apontando tendências, polos de pesquisa, campos pesquisados e autores influentes na área, bem como journals internacionais que trabalham com o tema.

\section{Fundamentação teórica}

Kotler (1973) foi o pioneiro em tratar da importância da atmosfera em um ambiente, ao sugerir que há mais na experiência do cliente do que o produto ou serviço, abordando a atmosfera ou o ambiente físico como possíveis influências na decisão de compra. Ele inicialmente identificou a essência do ambiente físico do varejo e sua capacidade de evocar respostas emocionais por meio da visão, som, cheiro e toque. Após seus estudos, diversos autores trataram da importância de fatores intangíveis na experiência do consumidor, reforçando a ideia de que aromas, temperatura, iluminação e cores do ambiente influenciam na percepção da comida, as escolhas e a quantidade de alimento consumido (Kontukoski, Paakki, Thureson, Uimonen, \& Hopia, 2016).

Segundo Hansen, Jensen e Gustafsson (2005), a experiência gastronômica, "Food Experience", pode ser definida em cinco pontos: o produto principal, o interior do restaurante, as relações sociais pessoais, a companhia e a atmosfera. $\mathrm{O}$ produto principal refere-se a todas as impressões sensoriais ao consumir os pratos, desde o paladar, por meio do sabor da comida, até a disposição da mesa e a forma de apresentação das comidas e bebidas. O interior do restaurante diz respeito à composição geral do meio gastronômico, como as cores, móveis e decoração. As relações sociais pessoais vinculam-se às relações de clientes com outros clientes, e de clientes com os funcionários, em aspectos como a educação e atenção. A companhia são as pessoas que estão juntas no mesmo grupo, o qual pode ser separado entre pessoal e de 
Cardoso, L. O., Ferreira, F. L., Christino, J. M. M., \& Noronha, A. L. S. (2022, jan./abr.). Conhecendo o campo sobre food experience: uma revisão bibliométrica dos últimos 20 anos na base web of Science

negócios. Por fim, tem-se a atmosfera do restaurante, que está relacionada tanto com itens tangíveis, como a arte e qualidade da mobília, quanto itens intangíveis, como música, vibe e configuração do espaço.

Já para Jang e Namkung (2009), em um restaurante, diversos estímulos podem influenciar no estado emocional do cliente. Dessa forma, esses estímulos e as experiências vivenciadas englobam recursos tangíveis e intangíveis, como atributos do produto, ambientes físicos e aspectos do serviço. Os atributos do produto relacionam-se com as características da comida, que inclui o sabor atraente, frescor, variedade de itens de menu e apresentação do prato. O ambiente físico diz respeito à utilização do espaço visual e auditivo, como o design, iluminação e música ambiente. Finalmente, a qualidade do serviço concerne à relação entre o consumidor e o meio gastronômico, como confiabilidade, empatia e capacidade de resposta do prestador de serviço.

Como discursado, "Food Experience" compreende uma experiência sensorial e deve levar em consideração a situação de uso e o contexto de consumo (Schifferstein, 2015). Envolve a atmosfera/ambientação do restaurante (Jang \& Namkung, 2009; Wu \& Liang, 2009; Longart, Wickens, \& Bakir, 2017; Peng \& Chen, 2015), performance do pessoal deste restaurante e sua interação com o cliente (Wu \& Liang, 2009), prestação de serviço de alta qualidade (Jang \& Namkung, 2009; Wu \& Liang, 2009; Longart, Wickens, \& Bakir, 2017; Peng \& Chen, 2015) e atributos relacionados à instalação, ao preço, à imagem do restaurante e à comida e bebida (Longart, Wickens, \& Bakir, 2017). A autenticidade também se mostrou um atributo essencial em "Food Experience" (Gregorash, 2017).

Song e Qu (2017) abordam a importância de "Food Experience", visto que, como a indústria da hospitalidade oferece serviços que enfatizam um componente experiencial em comparação com produtos manufaturados, as emoções sentidas durante as experiências de consumo são particularmente importantes na avaliação geral da satisfação. Dessa forma, um bom entendimento das influências na experiência de jantar do cliente é essencial para o sucesso de marketing na indústria de restaurantes (Teng \& Chang, 2013).

Assim, os estabelecimentos gastronômicos representam estruturas de hospitalidade com significações mais amplas que a nutrição em si, em que a apresentação dos alimentos, os utensílios de mesa e a situação de consumo, tal qual itens imateriais da experiência alimentar, como os significados associados aprodutos, sentimentos e emoções, (Schifferstein, 2015) são responsáveis por criar momentos positivos, negativos ou até mesmo neutros para os consumidores (Gregorash, 2017). Esses fatores vão além das propriedades analisadas 
Cardoso, L. O., Ferreira, F. L., Christino, J. M. M., \& Noronha, A. L. S. (2022, jan./abr.). Conhecendo o campo sobre food experience: uma revisão bibliométrica dos últimos 20 anos na base web of Science

regularmente pela administração de restaurantes e conceituam vivência e valor simbólico (Gândara, Gimenes, \& Mascarenhas, 2009). É fundamental que uma organização entenda sua relação com o valor das experiências gastronômicas (Schifferstein, 2015), para que ela possa se adequar aos anseios de seus consumidores e, assim, manter-se atualizada e em constante evolução.

Logo, quando o objetivo é entender "Food Experience" no turismo, a experiência ocorre por meio da imersão do turista no ambiente local, onde o consumo alimentar do turista pode constituir um aspecto importante da experiência holística de férias e contribuir para a memorização de uma viagem (Quan \& Wang, 2004; Sthapit, 2017; Hendijani, 2016); ligadas à cultura, ao conhecimento, à novidade, autenticidade, ao significado e a experiências diversas visuais e não visuais (Adongo, Anuga \& Dayour, 2015; Goolaup \& Moosberg, 2016; Sthapit, 2017; Quan \& Wang, 2004; Björk \& Kauppinen-Räisänenb, 2019). Devido a esses fatores, os restaurantes devem ser mais tradicionais na escolha dos seus ingredientes, a fim de manter o sabor distinto, a novidade e a autenticidade de pratos locais, bem como incentivar uma interação entre o prestador de serviços e os consumidores, incluindo histórias sobre as especialidades e cultura alimentar local (Sthapit, 2017). O termo "Food Experience" tem uma relação positiva com a intenção de se visitar a cidade de origem da culinária (Pu, Teah \& Phau, 2019).

\section{Metodologia}

Visando analisar as publicações acerca do tema "Food Experience", este artigo teve como estratégia uma revisão bibliométrica, que consiste na aplicação de técnicas matemáticas e estatísticas ao estudo de publicações em diversos campos de pesquisa (Diodato \& Gellatly, 2013). A bibliometria é um mecanismo de pesquisa bem estabelecido em ciências da informação. Esse método é um modo quantitativo de investigar a evolução dos trabalhos científicos sobre determinada temática, para analisar tendências em ciência e inovação, além de produzir uma avaliação do desempenho desses estudos (Van Raan, 2003; Neff \& Corley, 2009). A análise bibliométrica pode fornecer uma visão macroscópica de um determinado campo para os pesquisadores e tem sido usada em muitos campos científicos (Jia, Dai, \& Guo, 2014).

O tema central desta revisão consiste na busca das publicações sobre o tema "Food Experience". A pesquisa foi efetuada na base de dados Web of Science, por meio da análise de diversos aspectos, como o volume de publicações, suas tendências temporais, principais autores 
Cardoso, L. O., Ferreira, F. L., Christino, J. M. M., \& Noronha, A. L. S. (2022, jan./abr.). Conhecendo o campo sobre food experience: uma revisão bibliométrica dos últimos 20 anos na base web of Science

e journals, países onde as pesquisas se concentram e se identificam os principais segmentos que estudam o tema em foco.

O software utilizado foi o CiteSpace, um programa de computador disponível gratuitamente, escrito em Java, para visualizar e analisar a literatura científica, dando como resultado a frequência e a centralidade dos artigos estudados e suas referências (Chen, Song, Yuan, \& Zhang, 2008). A frequência de uma categoria, autor, ou palavra-chave, por exemplo, é caracterizada no CiteSpace pelo tamanho dos círculos; aqueles que apresentam um maior diâmetro são considerados mais frequentes, ou seja, aparecem uma quantidade de vezes maior nas amostras. Já a centralidade, que diz respeito à influência que determinado tema apresenta no campo de pesquisa, é representada por aros arroxeados, sendo que os que possuem maior intensidade representam os mais centrais, ou seja, são mais influentes. Somente a base Citespace apresenta análise da centralidade.

Além disso, a rede estabelecida pelo CiteSpace realiza a divisão de clusters, que são agrupamentos de referências. A nomeação desses agrupamentos decorreu das palavras-chave utilizadas, os quais são avaliados a partir de sua modularidade e silhueta. De acordo com Li, Ma e Qui (2017), as conexões entre os clusters são definidas por meio da Modularidade Q, um valor entre 0 a 1 , considerando que os valores próximos a 1 apontam relações mais próximas entre os clusters. Já a silhueta determina a homogeneidade de cada cluster. Os valores da silhueta média encontram-se entre -1 e 1 . Quanto mais próximos de 1 , mais consistentes ou semelhantes são os clusters em relação ao conteúdo (Li, Ma, \& Qu, 2017).

O estudo teve como intervalo de tempo um período de vinte anos, de 1999 a 2019. Os termos de buscas utilizados na Web of Science foram as palavras-chave "Food Experience", "pubs consum*", "restaurant consum*", "restaurants consum*”, "bar consum*" e "bars consum*”. Essa busca resultou em 187 artigos, e não houve nenhuma filtragem. Por fim, os resultados foram extraídos da base de dados e baixados para o CiteSpace.

\section{Revisão bibliométrica}

\subsection{Análise do volume de publicações e tendências temporais}

Para a análise do volume de publicações indexadas na Web of Science, consideraram-se os 187 artigos encontrados na busca, descrita na seção metodologia. Com isso, mapeou-se a trajetória das publicações nos 20 anos que compreendem o corpus da pesquisa, destacando-se aquelas com maior número de citações. Para uma melhor visualização, ver a Figura 1. 
Cardoso, L. O., Ferreira, F. L., Christino, J. M. M., \& Noronha, A. L. S. (2022, jan./abr.). Conhecendo o campo sobre food experience: uma revisão bibliométrica dos últimos 20 anos na base web of Science

Nos vinte anos pesquisados, percebe-se que estudos sobre Food Experience encontravam-se em estágio incipiente na primeira década de 2000, variando de 1 a 4 publicações por ano. Em 2009, o número de publicações atinge o pico, com 9 publicações — o maior até então. Em 2010, ocorre uma queda nas publicações, mas, a partir daí, o número de publicações cresce exponencialmente, atingindo mais um pico de publicação em 2014, e depois em 2018. Os últimos 5 anos de publicação analisados acumulavam cerca de $63,7 \%$ de toda a produção analisada. Apesar do crescimento exponencial percebido após 2008, decidiu-se focar nos picos de publicação e no primeiro ano de análise — sendo eles: 2000, 2009, 2014 e 2018. A Quadro 1 traz um panorama sobre os artigos mais citados no campo de Food Experience nos anos em questão.

\section{Figura 1.}

\section{Evolução do Número de Publicações Sobre "Food Experience"}

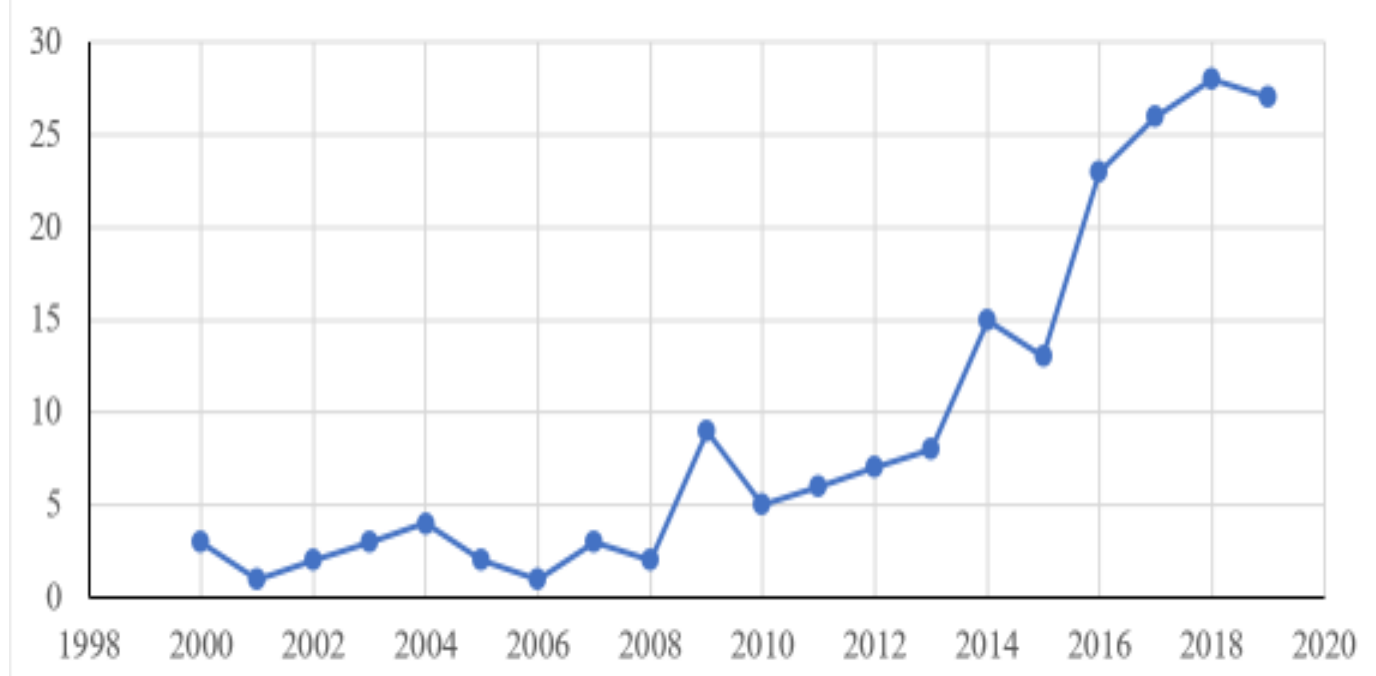

Fonte: Web of Science (2020). 
Cardoso, L. O., Ferreira, F. L., Christino, J. M. M., \& Noronha, A. L. S. (2022, jan./abr.). Conhecendo o campo sobre food experience: uma revisão bibliométrica dos últimos 20 anos na base web of Science

\section{Quadro 1.}

Artigos Mais Citados nos Picos de Publicação

\begin{tabular}{|c|c|c|c|}
\hline Ref. & Citação & Artigo & Assunto \\
\hline $\begin{array}{l}\text { Frank e Kalisewick } \\
(2000)\end{array}$ & 11 & $\begin{array}{l}\text { Food Experience and } \\
\text { willingness to try novel } \\
\text { foods }\end{array}$ & $\begin{array}{l}\text { Estudo que indica a relação entre Food } \\
\text { Experience e a vontade de experimentar } \\
\text { novas comidas. O estudo, porém, é uma } \\
\text { "rapid communication" e não explica sua } \\
\text { teoria, metodologia ou discute seus } \\
\text { resultados. }\end{array}$ \\
\hline $\begin{array}{l}\text { Jang e Namkung } \\
(2009)\end{array}$ & 469 & $\begin{array}{l}\text { Perceived quality, emotions, } \\
\text { and behavioral intentions: } \\
\text { Application of an extended } \\
\text { Mehrabian-Russell model to } \\
\text { restaurants }\end{array}$ & $\begin{array}{l}\text { Utilizando modelagem de equações } \\
\text { estruturais, os autores sugerem que a } \\
\text { atmosfera do restaurante e o tipo de } \\
\text { serviço prestado são estímulos que } \\
\text { aumentam as emoções positivas nos } \\
\text { consumidores. }\end{array}$ \\
\hline $\begin{array}{l}\text { Pestek e Cinjarevic } \\
\text { (2014) }\end{array}$ & 42 & $\begin{array}{l}\text { Tourist perceived image of } \\
\text { local cuisine: the case of } \\
\text { Bosnian food culture }\end{array}$ & $\begin{array}{l}\text { Indicam dimensões da culinária local que } \\
\text { influenciam a satisfação de turistas com } \\
\text { Food Experience, sendo eles: "comida } \\
\text { única e herança cultural", "qualidade e } \\
\text { preço da comida", "benefícios nutritivos } \\
\text { da comida" e "imagem afetiva da } \\
\text { comida". }\end{array}$ \\
\hline $\begin{array}{l}\text { Goolaup, Soler e } \\
\text { Nunkoo (2018) }\end{array}$ & 25 & $\begin{array}{lr}\text { Developing a } & \text { Theory of } \\
\text { Surprise from } & \text { Travelers } \\
\text { Extraordinary } & \text { Food } \\
\text { Experiences } & \end{array}$ & $\begin{array}{l}\text { Os autores buscam entender a relação } \\
\text { entre experiências extraordinárias com } \\
\text { comida, capital cultural e teoria da } \\
\text { surpresa. Segundo os autores, aqueles } \\
\text { com alto capital cultural se surpreendiam } \\
\text { com a simplicidade/complexidade da } \\
\text { experiência, e aqueles com baixo capital } \\
\text { se surpreendiam com a genuinidade da } \\
\text { experiência. }\end{array}$ \\
\hline
\end{tabular}

Fonte: Dados da pesquisa (2021).

No ano 2000, ocorreram três publicações, em que apenas uma se referia a Food Experience precisamente, relacionando-o à vontade de experimentar novas comidas (Frank \& Kalisewick, 2000). No ano de 2009, entre as nove publicações indexadas, a de maior citação (469) é a de Jang e Namkung (2009), que aborda, a partir de uma modelagem de equações estruturais, a forma como a atmosfera e o serviço de um meio gastronômico funcionam como estímulos que aumentam as emoções positivas, enquanto os atributos do produto, como a qualidade da comida, agem para aliviar as respostas emocionais negativas. A grande maioria dos artigos publicados neste ano tratam do consumo de restaurante, e aspectos sensoriais e ambientais que o circundam - mas sem citar Food Experience. O ano de 2014 possui 15 publicações, mas poucos são os artigos que realmente citam o construto Food Experience enquanto indexador. Eentre estes, o de maior citação é o de Pestek e Cinjarevic (2014), que indica dimensões de Food Experience que atuam na satisfação com experiências turísticas. 
Cardoso, L. O., Ferreira, F. L., Christino, J. M. M., \& Noronha, A. L. S. (2022, jan./abr.). Conhecendo o campo sobre food experience: uma revisão bibliométrica dos últimos 20 anos na base web of Science

Finalmente, em 2018, o ano com maior número de publicações (28), tem-se o artigo de Goolaup, Soler e Nunkoo (2018) com o maior número de citações (25), discursando sobre experiências extraordinárias com comida, capital cultural e teoria da surpresa. Depreende-se desta análise que, mesmo com o número de publicações em ascendência, o construto Food Experience parece ser abordado por meio de pistas sobre a experiência sensorial e extrassensorial obtida com a prática de se alimentar, mas sem um aprofundamento sobre o construto em si, sua conceitualização, dimensões de pesquisa, antecedentes e consequentes o que passa a imagem de um campo de estudos ainda fragmentado e, ainda, embrionário.

\subsection{Autores mais produtivos}

Neste ponto da pesquisa, buscou-se analisar os autores mais produtivos, que publicaram na Web of Science sobre "Food Experience". Foram encontrados 603 autores, e, entre eles, os de maior produtividade são: SooCheong Jang, Lydia Hanks, Nathaniel D. Line e Hendrik N. J. Schifferstein.

SooCheong (Shawn) Jang é o autor com maior produtividade (5 publicações). Ele é especialista em estratégias de negócios baseadas em informações financeiras e comportamento do consumidor. Jang é professor de Gestão de Hospitalidade e Turismo na Universidade Purdue e atua nos conselhos editoriais de diversos periódicos de turismo, como o Tourism Management e o Journal of Hospitality and Tourism Research. Com 344 citações, seu artigo de maior destaque indexado na Web of Science é "Perceived quality, emotions, and behavioral intentions: Application of an extended Mehrabian-Russell model to restaurants" publicado pelo Journal of Business Research em 2009. Essa pesquisa aborda os fatores em um meio gastronômico que funcionam como estímulos emocionais positivos e negativos para o consumidor. Outro artigo de destaque desse autor é "Customer complaints in restaurants: Do they differ by service stages and loyalty levels?". A pesquisa obteve 22 citações, foi publicada no International Journal of Hospitality Management e investiga se os consumidores de restaurantes respondem de maneira diferente a falhas de serviço em diferentes estágios de serviço e níveis de fidelidade.

Lydia Hanks é a segunda autora com o maior número de publicações sobre "Food Experience". Hanks é professora de hospitalidade na Universidade do Estado da Flórida e faz parte do conselho editorial do Journal of Hospitality and Tourism Insights and Tourism Analysis. Suas pesquisas são voltadas para as áreas de marketing, como comportamento do 
Cardoso, L. O., Ferreira, F. L., Christino, J. M. M., \& Noronha, A. L. S. (2022, jan./abr.). Conhecendo o campo sobre food experience: uma revisão bibliométrica dos últimos 20 anos na base web of Science

consumidor, marketing de serviços e responsabilidade social corporativa. A publicação com maior relevância de Hanks, com 24 citações, é "Sustainability communication: The effect of message construals on consumers' attitudes towards green restaurants". Este artigo, do ano de 2016, foi escrito juntamente a outro autor destaque no tema "Food Experience", Nathaniel D. Line e aborda sobre qual mensagem de sustentabilidade transmitida pelos meios gastronômicos resulta em atitudes positivas do consumidor. Para a realização da pesquisa, além de percepções teóricas, foram coletados dados de uma amostra de consumidores de restaurantes nos Estados Unidos.

Nathaniel D. Line é um profissional especializado no ramo de Hospitalidade e Turismo, com mais de 50 artigos publicados ao longo de sua carreira nessa área. Sua publicação indexada na Web of Science sobre "Food Experience" com maior número de citações (24) é "Sustainability communication: The effect of message construals on consumers' attitudes towards green restaurants". Essa pesquisa foi publicada no International Journal of Hospitality Management e escrita juntamente à autora mencionada anteriormente, Lydia Hanks.

Por fim, Hendrik N. J. Schifferstein é o editor-chefe do International Journal of Food Design e é especialista em estudos sobre a percepção do paladar e olfato e comportamento do consumidor em relação a produtos alimentícios. O principal artigo de Schifferstein trata sobre os tipos e as fontes das emoções experimentadas por indivíduos em resposta à degustação ou ingestão de alimentos. Foi publicado no ano de 2007 no journal Apettite e intitulado "Sources of positive and negative emotions in Food Experience”. Entre todas as pesquisas indexadas na Web of Science dos quatro autores mais relevantes sobre "Food Experience", essa foi a publicação que obteve o maior número de citações (246).

\subsection{Análise das palavras-chaves}

As palavras-chave constituem sinônimos que definem o conceito-chave de pesquisas sobre determinado tema, o que as torna uma parte fundamental da pesquisa bibliométrica, uma vez que pode mostrar quais são os temas e as tendências abordadas em determinado campo de pesquisa (Xiang, Wang, \& Liu, 2017).

$\mathrm{Na}$ análise de palavras-chaves, foram consideradas as 20 mais frequentes em pesquisas sobre "Food Experience" e as 10 com maior centralidade. O termo "Food Experience" (12 de frequência e 0.02 de centralidade) foi voluntariamente excluído, por ser o termo-chave usado na busca para a pesquisa bibliométrica. 
Cardoso, L. O., Ferreira, F. L., Christino, J. M. M., \& Noronha, A. L. S. (2022, jan./abr.). Conhecendo o campo sobre food experience: uma revisão bibliométrica dos últimos 20 anos na base web of Science

\section{Tabela 1.}

As Palavras Mais Frequentes e Centrais Sobre "Food Experience" (1999/2019)

\begin{tabular}{rrcrcc}
\hline Freq. & Central. & Palavras-chave & \multicolumn{1}{c}{ Freq. } & Central. & Palavras-chave \\
\hline 18 & 0.29 & Quality & 13 & $\mathbf{0 . 3 5}$ & Impact \\
18 & 0.14 & Satisfaction & 18 & $\mathbf{0 . 2 9}$ & Quality \\
17 & 0.08 & Experience & 15 & $\mathbf{0 . 2 1}$ & consumption \\
15 & 0.21 & Consumption & 13 & $\mathbf{0 . 1 6}$ & Restaurant \\
15 & 0.14 & Obesity & 12 & $\mathbf{0 . 1 5}$ & Perception \\
15 & 0.01 & Model & 9 & $\mathbf{0 . 1 5}$ & Food \\
13 & 0.35 & Impact & 8 & $\mathbf{0 . 1 5}$ & customer \\
& & & & $\mathbf{0 . 1 4}$ & satisfaction \\
13 & 0.16 & Restaurant & 18 & $\mathbf{0 . 1 4}$ & Obesity \\
12 & 0.10 & Behavior & 15 & $\mathbf{0 . 1 3}$ & Choice \\
12 & 0.15 & Perception & 5 & $\mathbf{0 . 1 1}$ & local food \\
10 & 0.11 & local food & 10 & & \\
9 & 0.15 & Food & & & \\
8 & 0.15 & customer satisfaction & & & \\
7 & 0.02 & Emotion & & & \\
7 & 0.07 & energy intake & & & \\
6 & 0.11 & diet quality & & & \\
6 & 0.04 & Antecedente & & & \\
5 & 0.06 & Tourism & & & \\
5 & 0.13 & Choice & &
\end{tabular}

Fonte: Elaborada pelos autores (2020).

A palavra Quality obteve a maior frequência (18) e a segunda maior centralidade (0.29). Ela está ligada com as palavras: behavior, customer satisfaction, diet quality, environment, health e obesity. Considerando as interpretações do conceito "Food Experience", é um termo que se relaciona principalmente com as seguintes áreas: (i) Gastronomia e Administração, referente à experiência que o ambiente gastronômico oferece e os motivos que levam à satisfação do consumidor; e (ii) Ciências biológicas e nutrição, envolvendo experimentos com comida e outros componentes que envolvem alimentação, bem como assuntos ligados à saúde e obesidade.

O termo Satisfaction divide a posição de maior frequência (18), entretanto está em oitava posição quanto à centralidade (0.14). Essa palavra se relaciona com: authenticity, choice, experience, impact, local food, perception e preference. Diversos estudos analisam como as conexões estabelecidas entre o consumidor e o meio gastronômico influenciam o nível de satisfação do cliente. Esse é um ponto essencial dentro do tema "Food Experience", visto que, ao analisar o comportamento do consumidor, é preciso determinar os estímulos gerais do serviço, no empenho de compreender o papel da experiência nos meios gastronômicos. Entre os artigos que pesquisam acerca de satisfação, tem-se a pesquisa de Wu e Liang (2009) que visa 
Cardoso, L. O., Ferreira, F. L., Christino, J. M. M., \& Noronha, A. L. S. (2022, jan./abr.). Conhecendo o campo sobre food experience: uma revisão bibliométrica dos últimos 20 anos na base web of Science

examinar a associação entre os elementos do encontro de serviço, o valor experiencial e a satisfação do cliente.

"Experience" tem a terceira maior frequência (17), entretanto possui uma centralidade considerada baixa (0.08). Ela relaciona-se com as palavras: behavioral intention, emotion, food, health, local food, perception e satisfaction. A conexão da palavra experiência com saúde, emoção e intenção comportamental demonstra a ligação do tema com estudos na área da administração e nutrição, voltados para o comportamento e escolha do consumidor de acordo com suas emoções, bem como a ligação da experiência gastronômica com a saúde. Estudos ligados a como os consumidores identificam, classificam e divulgam suas experiências alimentares é um fator relevante nos setores alimentícios.

Outra palavra-chave importante é Impact, pois apresenta a maior centralidade entre todos os termos (0.35), entretanto não apresenta uma frequência significativamente alta (13). Essa palavra está ligada com: antecedent, behavior, customer satisfaction, intention, preference, restaurant, satisfaction e service. Consumption possui a terceira maior centralidade (0.21) e a quarta maior frequência (15). Esse termo possui ligação com: antecedent, authenticity, choice, energy intake, Food Experience, local food, preference, restaurant, satiety e tourism.

A conexão das palavras-chave na área de pesquisa de "Food Experience" pode ser analisada usando um mapa de rede de correlações de palavras-chave, como mostra a Figura 2. O tamanho dos círculos representa a quantidade de publicações; os que possuem os maiores raios caracterizam as palavras que têm maior frequência, como quality, satisfaction e consumption. A espessura dos elos representa a força das colaborações (Van Nunen, Li, Reniers, \& Ponnet, 2018). Já os círculos com o aro arroxeado possuem as maiores centralidades. As palavras mais centrais, como impact, quality e consumption, possuem os maiores aros arroxeados. 
Cardoso, L. O., Ferreira, F. L., Christino, J. M. M., \& Noronha, A. L. S. (2022, jan./abr.). Conhecendo o campo sobre food experience: uma revisão bibliométrica dos últimos 20 anos na base web of Science

\section{Figura 2.}

Mapa de Rede de Correlações de Palavras-Chave

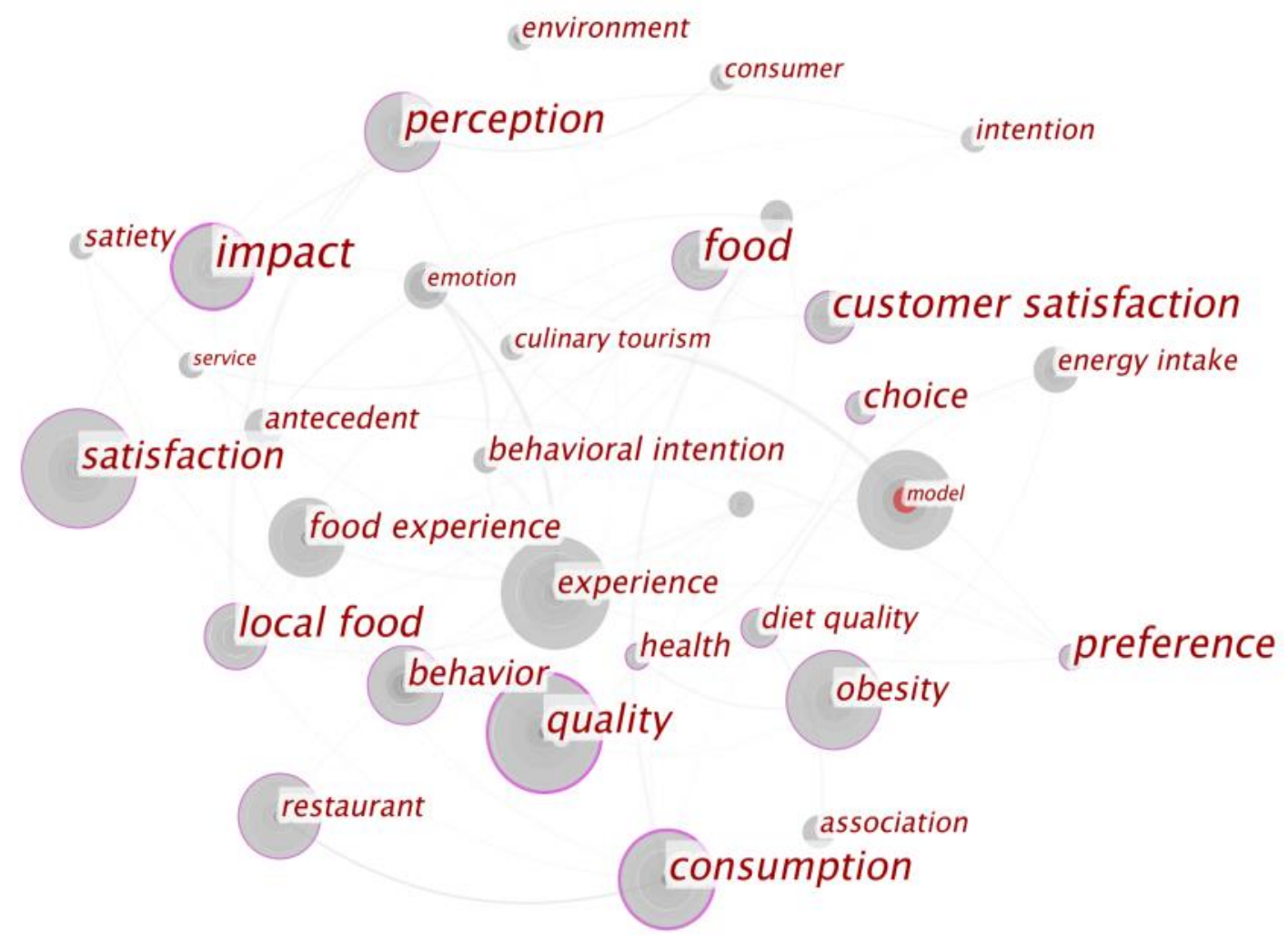

Fonte: Elaborada pelos autores (2020).

Considerando as palavras-chave mais frequentes e centrais, conclui-se que há uma tendência de estudos relacionados ao comportamento do consumidor, buscando identificar os fatores que influenciam na satisfação, experiência e percepção dos clientes, bem como os impactos que isso gera para os meios gastronômicos. Constatam-se da análise algumas observações. Primeiro, behavior e choice são palavras com alta centralidade e baixa frequência, ou seja, estudos que foquem no consumidor, especificamente aprofundando na análise do que faz com que ele escolha Food Experience — tomada de decisão —, pode ser um campo frutífero de pesquisa. Segundo, local food também obteve alta centralidade e baixa frequência - ou seja, pesquisar sobre a comida local e o Food Experience pode também ser promissor para pesquisas. 
Cardoso, L. O., Ferreira, F. L., Christino, J. M. M., \& Noronha, A. L. S. (2022, jan./abr.). Conhecendo o campo sobre food experience: uma revisão bibliométrica dos últimos 20 anos na base web of Science

\subsection{Análise de categorias}

A divisão de categorias é um instrumento útil para analisar os campos de estudo e as características das publicações na Web of Science, auxiliando na separação das opções de artigos para ler e consultar (Wang, Yu \& Ho, 2010). Cada artigo pode ser indexado em um campo temático.

Os 187 artigos analisados com o tema "Food Experience" no período de 20 anos (1999/2019) foram divididos em 25 categorias e apresentados na Tabela 2. Dentre elas, encontram-se com maior frequência Social Sciences - Other Topics (45) e Hospitality, Leisure, Sport \& Tourism (44). Entretanto, essas duas categorias possuem suas centralidades zeradas, o que mostra que, apesar de haver um número elevado de publicações, elas não se destacam nesse campo, por não ter forte associação entre si e com outras áreas.

Tabela 2.

Áreas de Concentração das Categorias de "Food Experience" de 1999 A 2009

\begin{tabular}{cccc}
\hline Frequência & Centralidade & Ano & Categorias \\
\hline 45 & 0.00 & 2009 & SOCIAL SCIENCES - OTHER TOPICS \\
44 & 0.00 & 2009 & HOSPITALITY, LEISURE, SPORT \& TOURISM \\
26 & 0.20 & 2009 & BUSINESS \& ECONOMICS \\
22 & 0.17 & 2013 & FOOD SCIENCE \& TECHNOLOGY \\
20 & 0.08 & 2009 & NUTRITION \& DIETETICS \\
13 & 0.27 & 2015 & MANAGEMENT \\
9 & 0.23 & 2016 & ENVIRONMENTAL SCIENCES \& ECOLOGY \\
8 & 0.00 & 2015 & BUSINESS \\
8 & 0.10 & 2016 & PUBLIC, ENVIRONMENTAL \& OCCUPATIONAL \\
& & & HEALTH \\
6 & 0.01 & 2015 & COMPUTER SCIENCE, INFORMATION SYSTEMS \\
6 & 0.01 & 2015 & COMPUTER SCIENCE \\
6 & 0.00 & 2014 & SOCIOLOGY \\
4 & 0.00 & 2000 & PSYCHOLOGY \\
4 & 0.03 & 2016 & SCIENCE \& TECHNOLOGY - OTHER TOPICS \\
4 & 0.00 & 2019 & ENVIRONMENTAL STUDIES \\
3 & 0.17 & 2019 & ENVIRONMENTAL SCIENCES \\
2 & 0.00 & 2004 & ENTOMOLOGY \\
2 & 0.00 & 2018 & PSYCHOLOGY, MULTIDISCIPLINARY \\
2 & 0.00 & 2017 & BIOTECHNOLOGY \& APPLIED MICROBIOLOGY \\
2 & 0.00 & 2008 & BEHAVIORAL SCIENCES \\
2 & 0.00 & 2019 & COMPUTER SCIENCE, THEORY \& METHODS \\
2 & 0.00 & 2019 & GREEN \& SUSTAINABLE SCIENCE \& TECHNOLOGY \\
2 & 0.00 & 2018 & ENGINEERING, ELECTRICAL \& ELECTRONIC \\
2 & 0.15 & 2016 & ECONOMICS \\
2 & 0.00 & 2018 & ENGINEERING \\
\hline
\end{tabular}

Fonte: Elaborada pelos autores (2020).

Percebe-se uma importância dos estudos sobre Food Experience dentro do campo de estudos da administração e economia. Na administração, têm-se Business \& Economics, com a 
Cardoso, L. O., Ferreira, F. L., Christino, J. M. M., \& Noronha, A. L. S. (2022, jan./abr.). Conhecendo o campo sobre food experience: uma revisão bibliométrica dos últimos 20 anos na base web of Science

terceira maior centralidade e frequência; e Management, com a maior centralidade e sexta maior frequência. Um detalhe é que Business \& Economics tem o início das indexações em 2009, o que justifica sua alta produção e relevância, mas Management, por sua vez, começou suas indexações em 2015, o que a torna destaque para o campo de estudos. Da mesma forma, Economics tem suas indexações começando em 2016 e, a despeito de sua baixa frequência, possui a sexta maior centralidade. Pesquisas representadas pelas categorias com altas centralidades têm maior impacto na área de estudo (Qiu \& Liu, 2018). Essas informações dão sustentação à importância sobre os estudos ligando Food Experience ao comportamento do consumidor que levam à tomada de decisão, satisfação e percepção encontradas no tópico anterior.

Uma categoria que também se destaca é Environmental Sciences \& Ecology, que teve sua primeira publicação em 2016. Apesar de não ter grande frequência, apresentando 9 indexações, possui a segunda maior centralidade (0.23). Portanto, pode-se afirmar que o campo de ciências ambientais e ecologia são significativos nos estudos de "Food Experience". Essa categoria apresenta estudos que analisam a interação de fatores químicos e físicos da comida com o ambiente e os seres humanos. Dessa forma, não abrange especificamente a definição de "Food Experience" que é utilizado neste estudo, mas sim experimentos físicos, químicos e biológicos que envolvem alimentação.

A figura abaixo mostra a rede de conexão entre as categorias que envolvem a temática "Food Experience". É possível destacar os nós com o arroxeado nos aros, Management; Business \& Economics; Food Science \& Technology; Environmental Sciences \& Ecology como sendo as mais centrais da amostra, e os nós com maior diâmetro, ou seja, Social Sciences - Other Topics e Hospitality (Leisure) como sendo os com maior frequência. 
Cardoso, L. O., Ferreira, F. L., Christino, J. M. M., \& Noronha, A. L. S. (2022, jan./abr.). Conhecendo o campo sobre food experience: uma revisão bibliométrica dos últimos 20 anos na base web of Science

\section{Figura 3.}

Rede de Conexão das Categorias de "Food Experience" de 1999 a 2009

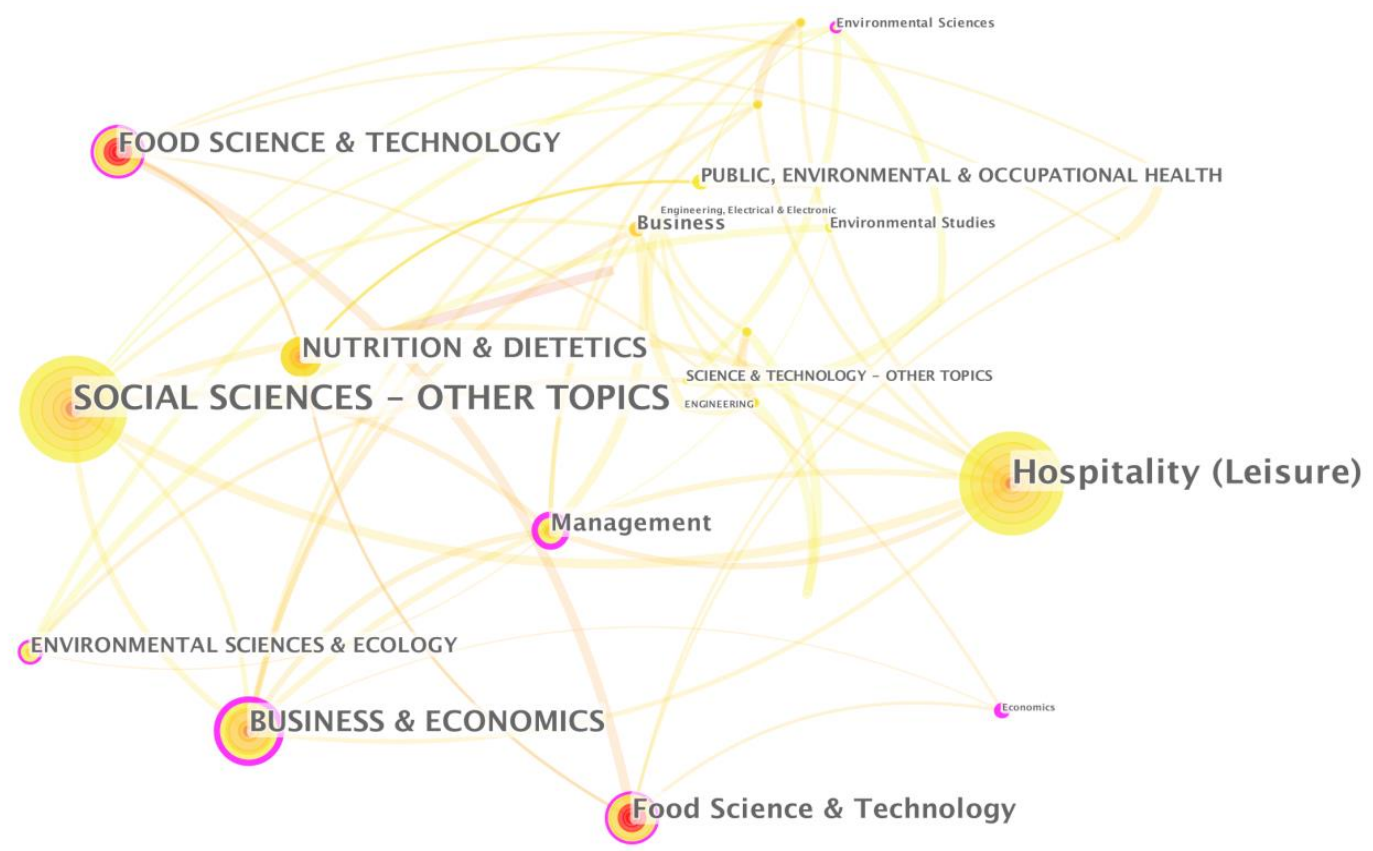

Fonte: Elaborado pelos autores (2020).

\subsection{Journals mais citados}

Em relação aos periódicos que ofertaram maior assistência às pesquisas do tema "Food Experience”, a Figura 4 mostra os 30 mais citados entre os 193 journals, de acordo com a frequência de ocorrência. Como é possível observar na Figura, os círculos com maior diâmetro representam os periódicos mais frequentes, e os que possuem o aro arroxeado com maior intensidade representam os mais centrais, ou seja, journals que têm forte influência no campo de pesquisa. Dentre eles, destacam-se os três journals com maior frequência: Appetite (53), Journal of Consumer Research (53) e Journal of Marketing (52). O journal Appetite obteve, além de uma alta frequência (53), a segunda maior centralidade (0.25), o que mostra que este é um periódico muito relevante na área de "Food Experience". A revista Appetite é especializada em influências culturais, sociais, psicológicas, sensoriais e fisiológicas na seleção e ingestão de alimentos e bebidas. 
Cardoso, L. O., Ferreira, F. L., Christino, J. M. M., \& Noronha, A. L. S. (2022, jan./abr.). Conhecendo o campo sobre food experience: uma revisão bibliométrica dos últimos 20 anos na base web of Science

\section{Figura 4.}

Rede de Journals Gerada Pelo Citespace

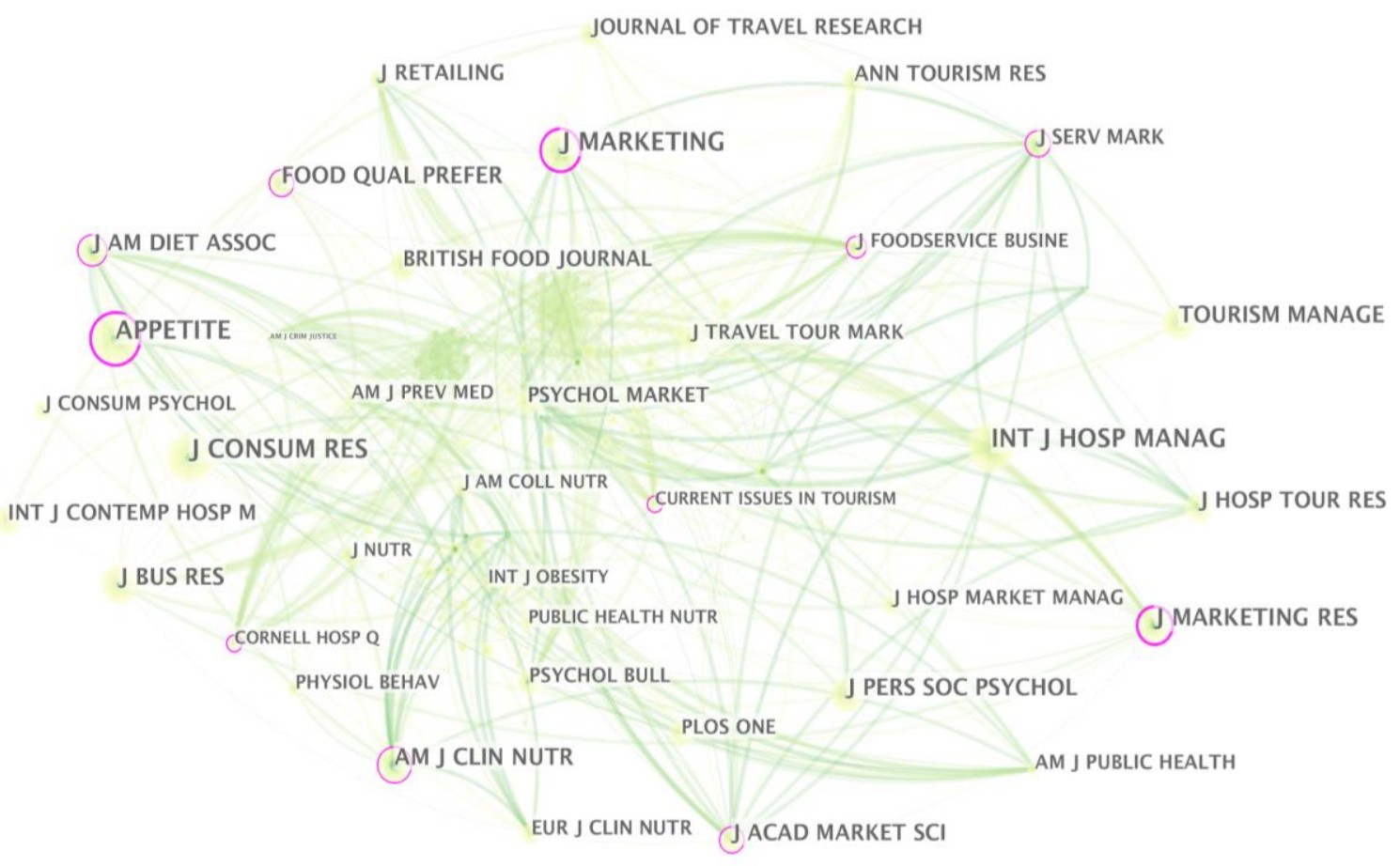

Fonte: Elaborada pelos autores (2020).

O Journal of Consumer Research, apesar de também possuir a maior frequência (53), possui uma centralidade considera baixa (0.05). Já o Journal of Marketing possui uma alta frequência (52) e a terceira maior centralidade (0.21). Este journal teve a sua fundação em 1936 e tem um papel significativo na definição do conteúdo e dos limites da disciplina de marketing, o que mostra a influência destes estudos dentro do marketing, especificamente no comportamento do consumidor.

Outro journal importante é o Journal of Marketing Research, que possui a maior centralidade (0.35) e a quinta maior frequência (40). As primeiras citações em pesquisas sobre "Food Experience" deste journal ocorreram no ano de 2009.

\subsection{Análise dos países de origem dos autores}

A análise dos países em que os artigos foram publicados é importante para entender de onde vêm as principais pesquisas sobre o tema "Food Experience". As publicações indexadas na Web of Science originam-se ao todo de 25 países. Entre esses 25 países, 14 encontram-se na Europa, 5 na Ásia, 2 na América do Norte, 2 na América do Sul e 2 na Oceania. Como é possível 
ver na tabela 4, os países com maior frequência são Estados Unidos, China, Inglaterra e Coreia do Sul. O grande número de publicações nesses países pode ser justificado pelo fato de os mesmos apresentarem fortes centros de pesquisa e estarem entre as 10 maiores potências mundiais, segundo US News and World Report (2020).

Podem-se observar na tabela 3 os países com maior frequência já relacionados.

Tabela 3.

Os Países com Maior Frequência e Centralidade

\begin{tabular}{cccccccc}
\hline Freq. & Cent. & Ano & País & Freq. & Cent. & Ano & País \\
\hline 83 & 0.17 & 2000 & USA & 2 & 0.00 & 2016 & CANADA \\
16 & 0.45 & 2009 & PEOPLES R CHINA & 2 & 0.00 & 2015 & TURKEY \\
11 & 0.47 & 2014 & ENGLAND & 2 & 0.00 & 2016 & INDONESIA \\
8 & 0.03 & 2017 & SOUTH KOREA & 2 & 0.00 & 2017 & NORWAY \\
8 & 0.17 & 2009 & NETHERLANDS & 2 & 0.20 & 2019 & NEW ZEALAND \\
7 & 0.00 & 2016 & FINLAND & 2 & 0.00 & 2019 & BRAZIL \\
6 & 0.06 & 2003 & FRANCE & 2 & 0.00 & 2017 & DENMARK \\
5 & 0.00 & 2013 & TAIWAN & 2 & 0.00 & 2018 & ECUADOR \\
4 & 0.00 & 2018 & AUSTRALIA & & & & \\
\hline
\end{tabular}

Fonte: Elaborada pelos autores (2020).

Os EUA possuem a maior frequência (87) e a quarta maior centralidade (0.17). Ele foi o primeiro país a ser citado, no ano de 2000. Os Estados Unidos apresentam ligação com a China, Coreia do Sul, Holanda e França. Um dos principais motivos para os Estados Unidos ser tão relevante é que os principais autores do tema "Food Experience" são norte-americanos, ou fazem parte de centros de pesquisa do país, como Lydia Hanks e Nathaniel D. Line. Como é possível visualizar na tabela 4, o artigo com maior número de citações (524) nos Estados Unidos foi intitulado "Towards a structural model of the tourist experience: An illustration from Food Experiences in tourism" e escrito por Shuai Quan e Ning Wang.

Com suas pesquisas iniciadas no ano de 2009, a República Popular da China possui a segunda maior frequência (16) e a segunda maior centralidade (0.45). A principal publicação deste país obteve 20 citações e foi escrita por Mingje Ji, Anthony Wong, Anita Eves e Caroline Scarles. O nome desse artigo é "Food-related personality traits and the moderating role of novelty-seeking in food satisfaction and travel outcomes". A China possui ligações com os Estados Unidos, Nova Zelândia, Inglaterra e Holanda. 
Cardoso, L. O., Ferreira, F. L., Christino, J. M. M., \& Noronha, A. L. S. (2022, jan./abr.). Conhecendo o campo sobre food experience: uma revisão bibliométrica dos últimos 20 anos na base web of Science

\section{Figura 5.}

Visualização da rede de países gerada pelo CiteSpace

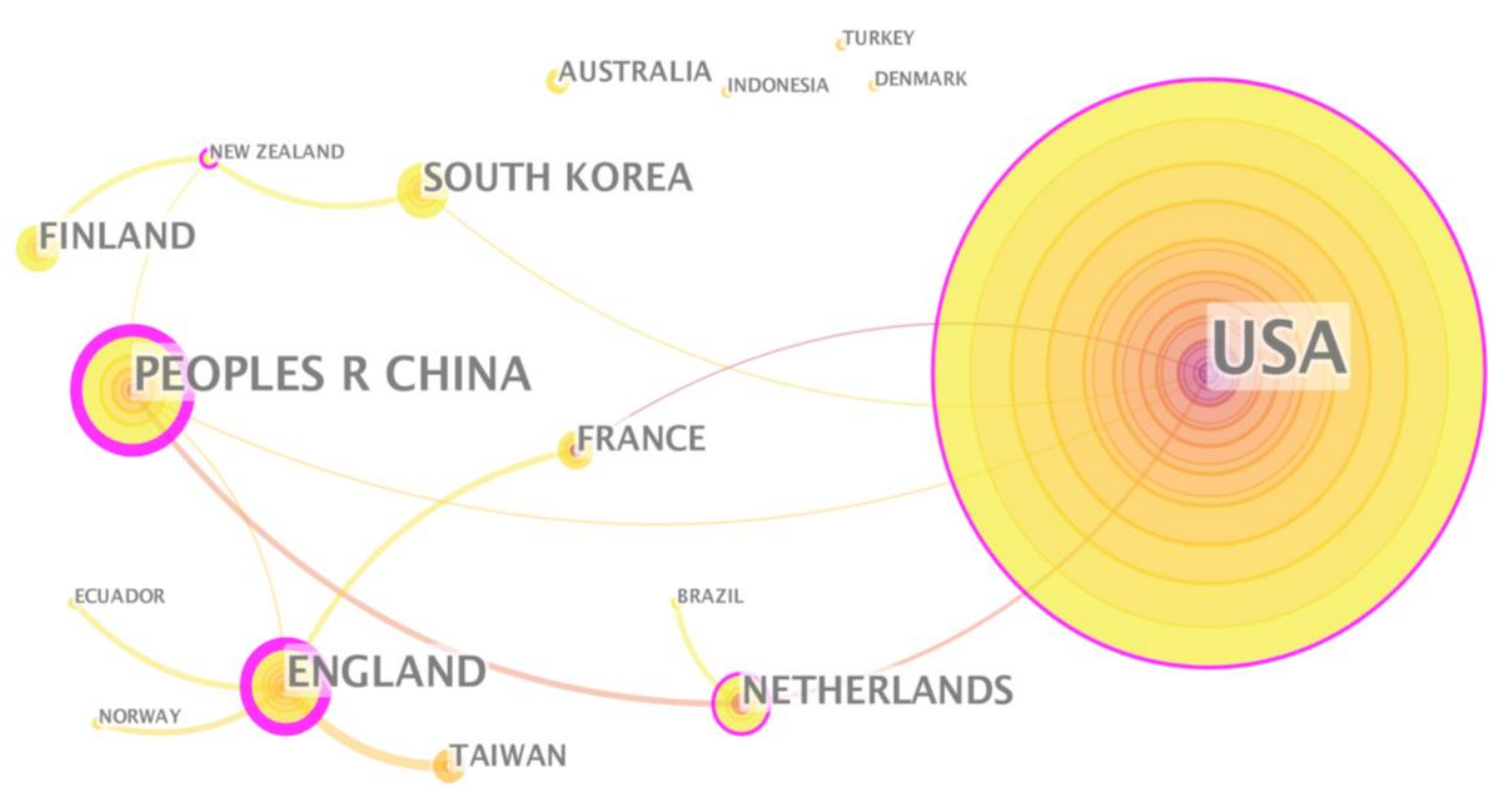

Fonte: Elaborada pelos autores (2020).

A Inglaterra possui a terceira maior frequência (11) e a maior centralidade (0.47), sendo que a alta centralidade mostra que esse é um país de grande relevância sobre o tema. Esse país conecta-se com a França, Taiwan, Noruega, China e Equador. A principal pesquisa da Inglaterra foi "The effects of luxury restaurant environments on diners' emotions and loyalty: Incorporating diner expectations into an extended Mehrabian-Russell model”, obteve 39 citações e é dos autores Annie Chen, Norman Peng e Kuang-peng Hung.

Por fim, com o intuito de localizar o Brasil em meio à pesquisa de "Food Experience", foi observado que o país possui apenas duas pesquisas sobre o tema e centralidade zero, com ambos os artigos do ano de 2019. São eles: (i) "Parental Perceived Travel Time to and Reported Use of Food Retailers in Association with School Children's Dietary Patterns", dos autores Mariane Alves, Maria Gabriela Pinho, Elizabeth Correa, Janaina das Neves e Francisco de Vasconcelos, com apenas uma citação, e (ii) "Taste and flavor in Food Experience: conceptual reflections”, escrito por Carina Palazzo, Camila Meirelles, Camila Japur e Rosa Diez-Garcia. O único país com o qual o Brasil possui ligações é a Holanda. Nenhum dos artigos publicados no Brasil retrata Food Experience na linha que este artigo visa investigar. A Tabela 4 traz um panorama acerca das principais publicações em cada um dos países mais relevantes para a pesquisa de Food Experience, de acordo com a base extraída da Web of Science. 
Cardoso, L. O., Ferreira, F. L., Christino, J. M. M., \& Noronha, A. L. S. (2022, jan./abr.). Conhecendo o campo sobre food experience: uma revisão bibliométrica dos últimos 20 anos na base web of Science

Tabela 4.

Os Artigos Mais Citados dos Países Mais Frequentes

\begin{tabular}{|c|c|c|c|c|}
\hline País & Artigo Mais Citado & Autor & Ano & $\begin{array}{l}\text { Número de } \\
\text { Citações }\end{array}$ \\
\hline USA & $\begin{array}{c}\text { Towards a structural model of the tourist } \\
\text { experience: An illustration from Food Experiences } \\
\text { in tourism }\end{array}$ & $\begin{array}{l}\text { Qual, S \& Wang, } \\
\text { N }\end{array}$ & 2004 & 524 \\
\hline $\begin{array}{l}\text { PEOPLES R } \\
\text { CHINA }\end{array}$ & $\begin{array}{l}\text { Food-related personality traits and the moderating } \\
\text { role of novelty-seeking in food satisfaction and } \\
\text { travel outcomes }\end{array}$ & Mingje Ji, et. al. & 2016 & 20 \\
\hline ENGLAND & $\begin{array}{c}\text { The effects of luxury restaurant environments on } \\
\text { diners' emotions and loyalty Incorporating diner } \\
\text { expectations into an extended Mehrabian-Russell } \\
\text { model }\end{array}$ & $\begin{array}{l}\text { Chen, A; Peng, } \\
\mathrm{N} \text { \& Hung, K }\end{array}$ & 2015 & 39 \\
\hline SOUTH KOREA & $\begin{array}{l}\text { Energy Intake from Restaurants Demographics and } \\
\text { Socioeconomics, 2003-2008 }\end{array}$ & $\begin{array}{l}\text { Powell, L; } \\
\text { Nguyen, B \& } \\
\text { Han, E }\end{array}$ & 2012 & 106 \\
\hline NETHERLANDS & $\begin{array}{l}\text { Sources of positive and negative emotions in Food } \\
\text { Experience }\end{array}$ & $\begin{array}{l}\text { Desmet, P \& } \\
\text { Schifferstein, H }\end{array}$ & 2008 & 276 \\
\hline
\end{tabular}

Fonte: Elaborada pelos autores (2021).

\subsection{Análise de autores mais citados}

Nas publicações sobre “Food Experience” entre 1999 e 2019, foram localizados cerca de 308 autores citados na rede do Citespace. Para fins de análise, consideraram-se os de frequência maior ou igual a 9, resultando em um total de 27 autores mais citados, como pode ser visto na Tabela 5. Também ocorreu a análise dos 10 autores citados com as maiores centralidades. Foi voluntariamente excluído o autor Anonymous, pois o mesmo poderia representar um conjunto de autores. 
Cardoso, L. O., Ferreira, F. L., Christino, J. M. M., \& Noronha, A. L. S. (2022, jan./abr.). Conhecendo o campo sobre food experience: uma revisão bibliométrica dos últimos 20 anos na base web of Science

\section{Tabela 5.}

Autores Citados Mais Frequentes e Mais Centrais de 1999 A 2019

\begin{tabular}{|c|c|c|c|c|c|c|c|}
\hline Freq. & Central. & Ano & Autor citado & Freq. & Central. & Ano & Autor Citado \\
\hline 23 & 0.13 & 2015 & [Anonymous] & 9 & 0.30 & 2011 & Kline R B \\
\hline 23 & 0.03 & 2013 & FORNELL C & 4 & 0.23 & 2011 & Paeratakul S \\
\hline 19 & 0.18 & 2009 & BITNER MJ & 9 & 0.22 & 2015 & King SC \\
\hline 19 & 0.15 & 2013 & Hair J F & 13 & 0.19 & 2009 & Bagozzi R P \\
\hline 16 & 0.02 & 2014 & Cohen E & 19 & 0.18 & 2009 & BITNER MJ \\
\hline 14 & 0.13 & 2015 & Ryu KiSang & 19 & 0.15 & 2013 & Hair J F \\
\hline 13 & 0.19 & 2009 & Bagozzi R P & 4 & 0.15 & 2016 & Aaker JL \\
\hline 13 & 0.04 & 2016 & Powell LM & 23 & 0.13 & 2015 & [Anonymous] \\
\hline 12 & 0.06 & 2015 & Koster EP & 14 & 0.13 & 2015 & Ryu KiSang \\
\hline 12 & 0.01 & 2009 & Zeithaml VA & 7 & 0.13 & 2009 & ANDERSON JC \\
\hline 12 & 0.01 & 2015 & Kivela J & 9 & 0.10 & 2016 & An R \\
\hline 12 & 0.01 & 2015 & Jang S & 11 & 0.08 & 2014 & Henderson JC \\
\hline 11 & 0.08 & 2014 & Henderson JC & & & & \\
\hline 11 & 0.04 & 2015 & Mak AHN & & & & \\
\hline 10 & 0.08 & 2015 & Kim YG & & & & \\
\hline 10 & 0.07 & 2015 & Liu YH & & & & \\
\hline 10 & 0.03 & 2015 & Oliver RL & & & & \\
\hline 10 & 0.03 & 2016 & Hall CM & & & & \\
\hline 10 & 0.02 & 2014 & Quan S & & & & \\
\hline 10 & 0.02 & 2015 & Han H & & & & \\
\hline 9 & 0.30 & 2011 & Kline R B & & & & \\
\hline 9 & 0.22 & 2015 & King SC & & & & \\
\hline 9 & 0.10 & 2016 & An R & & & & \\
\hline 9 & 0.06 & 2017 & Bjork P & & & & \\
\hline 9 & 0.03 & 2016 & Chang RCY & & & & \\
\hline 9 & 0.02 & 2015 & Hjalager AM & & & & \\
\hline 9 & 0.01 & 2013 & Parasuraman A & & & & \\
\hline
\end{tabular}

Fonte: Elaborada pelos autores (2020).

Entre os cinco autores mais citados, a maioria situa-se no campo da Administração, principalmente o setor de Marketing. O autor com maior frequência (23) é Claes Fornell, sendo que a primeira citação sobre ele ocorreu em 2013. Apesar da alta frequência, sua centralidade não foi relevante (0.03). Fornell é um autor sueco, especialista em medição de satisfação do cliente e medição de ativos. O artigo mais citado dele é "Evaluating structural equation models with unobservable variables and measurement error”, de 1981, com 62.599 citações. 
Cardoso, L. O., Ferreira, F. L., Christino, J. M. M., \& Noronha, A. L. S. (2022, jan./abr.). Conhecendo o campo sobre food experience: uma revisão bibliométrica dos últimos 20 anos na base web of Science

A segunda maior frequência (19) é dos autores Mary Jo Bitner e Joseph F. Hair. Bitner possui a quinta maior centralidade (0.18), e o ano em que teve o maior número de citações dentro do tema "Food Experience" foi 2016. Essa autora é editora-chefe do Journal of Service Research, e o seu artigo mais citado é "Services marketing: Integrating customer focus across the firm" do ano de 2000, com 16.296 citações. O outro autor com a segunda frequência mais alta, Joseph F. Hair obteve uma centralidade também considerada elevada (0.15). Este pesquisador norte-americano é especialista em análises multivariadas, e o seu artigo com o maior número de citações, "Multivariate data analysis", trata desse tema. Conclui-se que o método de análise quantitativo - área de especialidade de Joseph F. Hair — é o predominante dentro da área.

Outro autor a ser destacado é Rex B Kline, pois o mesmo obteve a maior centralidade (0.30), apesar de ter uma frequência reduzida (9). Kline é formado em psicologia, e seus estudos são focados na área da ciência do comportamento. Em 2008, ele publicou o livro "Becoming a Behavioral Science Researcher”. Uma observação é que, entre os cinco autores com maior frequência, apenas Bitner MJ aparece também na lista dos cinco mais centrais. A figura 6 mostra a rede de correlação dos autores citados feita pelo Citespace.

\section{Figura 6.}

Rede de Autores Citados de 1999 A 2019

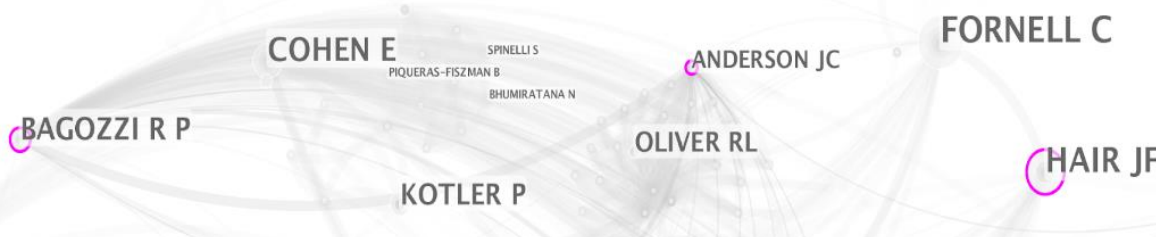

BITNER MJ

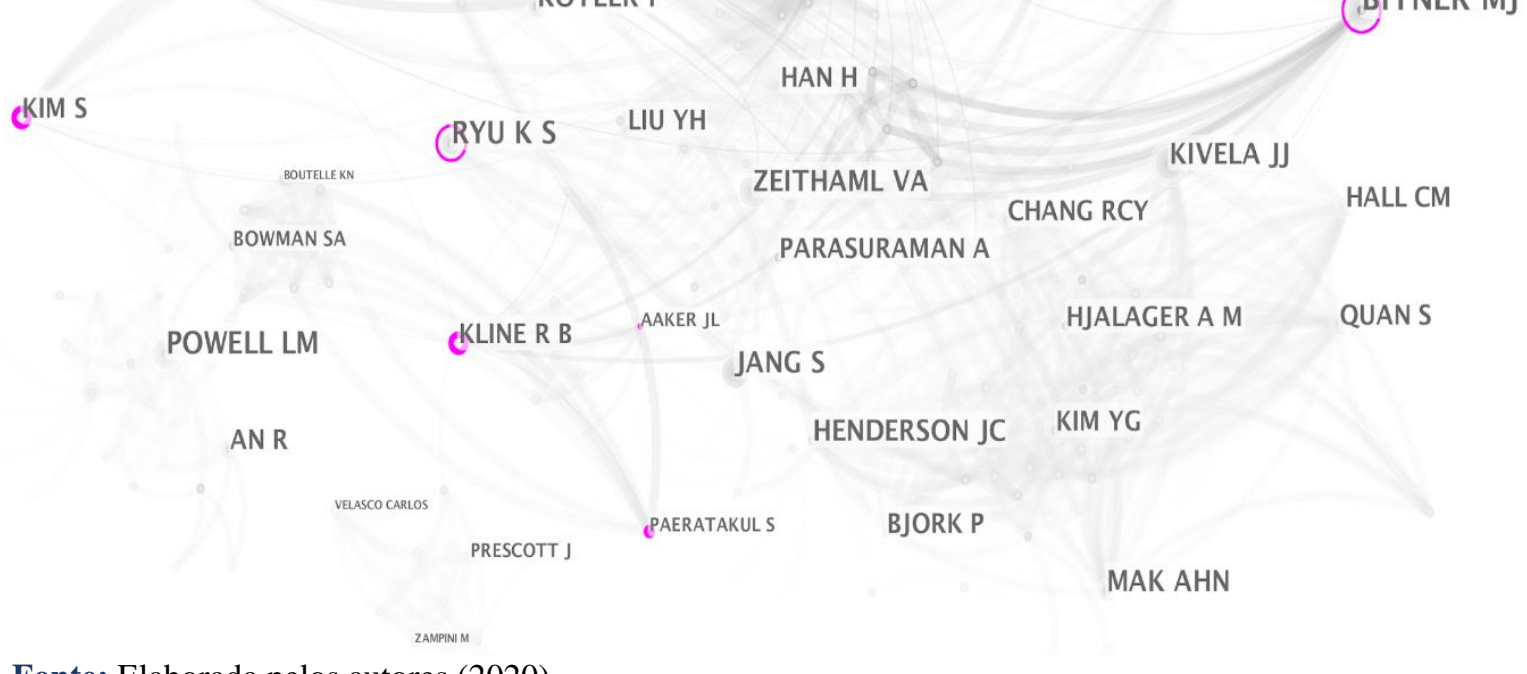

Fonte: Elaborada pelos autores (2020). 
Cardoso, L. O., Ferreira, F. L., Christino, J. M. M., \& Noronha, A. L. S. (2022, jan./abr.). Conhecendo o campo sobre food experience: uma revisão bibliométrica dos últimos 20 anos na base web of Science

\subsection{Análise de clusters sobre as referências citadas}

Após a análise das palavras-chave, foram formados agrupamentos de referências, por meio de clusters, a partir da rede estabelecida pelo Citespace. A nomeação desses agrupamentos decorreu das palavras-chave utilizadas.

Segundo Li, Ma e Qui (2017), as conexões entre os clusters são avaliadas por meio da Modularidade $\mathrm{Q}$, um valor que varia de 0 a 1 , e valores próximos a 1 revelam relações mais próximas entre os clusters. De um modo geral, os valores de Modularidade Q entre 0,4 e 0,8 são satisfatórios. Neste estudo, a modularidade foi de 0.774 , o que significa uma estruturação alta dos clusters. Já a silhueta define a homogeneidade de cada cluster. Os valores da silhueta média devem estar entre -1 e 1 . Valores próximos a 1 mostram que os clusters são altamente consistentes ou semelhantes em termos de conteúdo (Li, Ma \& Qui, 2017). O presente estudo obteve o valor de silhueta média de 0.7618 . Formaram-se 3 agrupamentos, mostrados na Figura 7, de acordo com as palavras-chave indexadas pelos artigos da amostra.

Figura 7.

Clusters de Palavras-Chaves

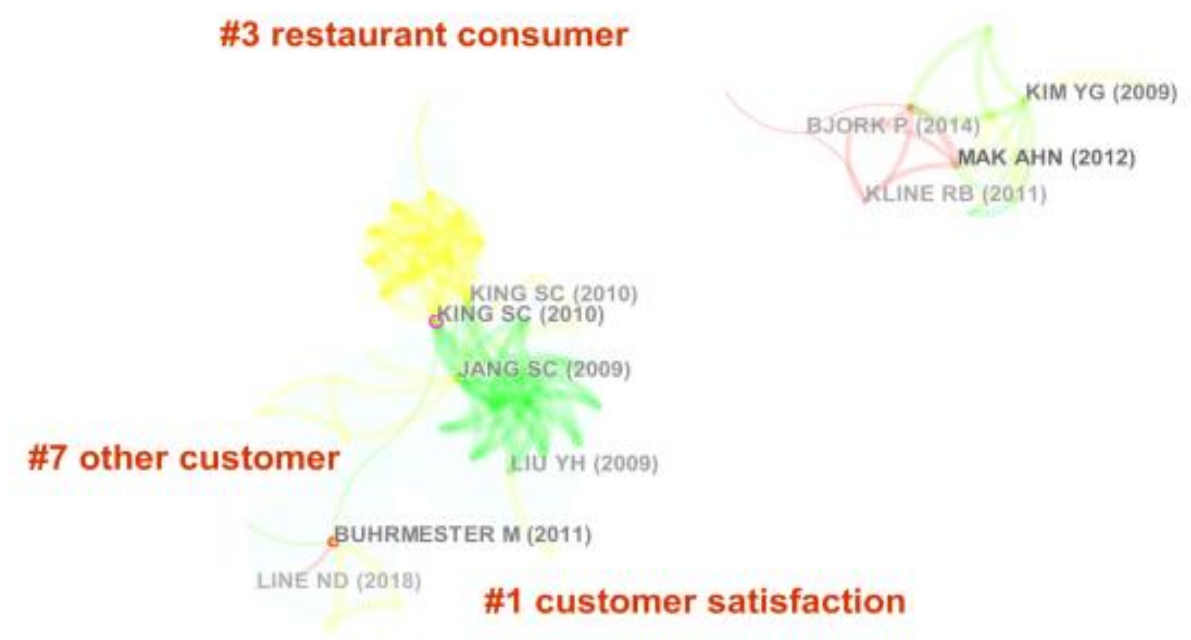

Fonte: Elaborada pelos autores (2020). 
Cardoso, L. O., Ferreira, F. L., Christino, J. M. M., \& Noronha, A. L. S. (2022, jan./abr.). Conhecendo o campo sobre food experience: uma revisão bibliométrica dos últimos 20 anos na base web of Science

O cluster com o maior número de membros foi o \#1, com 20 membros e valor de silhueta 0.937, com início das publicações datado de 2010. Ele foi denominado Customer Satisfaction e representa estudos voltados para a área de restaurantes de luxo, lealdade à marca, preocupação com a saúde, expectativa de jantar, experiência de consumo e qualidade. O cluster \#3 é o segundo mais populoso (13) e apresenta o maior valor de silhueta (0.954). O nome do cluster é Restaurant Consumer e também aborda os temas restaurantes de luxo e fidelidade, além de outras áreas, como medidas de expressão facial, expectativa, autorrelato de resposta emocional e degustação. O cluster \#7 possui o menor número de membros (6) e o menor valor de silhueta (0.923). Esse cluster foi nomeado Other Customer. Esse agrupamento trata de pesquisas que envolvem individualismo, necessidades sociais, atributos intrínsecos e extrínsecos, impacto, marca, consumo simbólico e status social. Os dois últimos clusters possuem o início das publicações em 2012.

\section{Conclusão}

O presente estudo objetivou mapear o campo de pesquisa a respeito de "Food Experience", que pode ser considerado um solo fértil para variadas formas de investigação ainda inexploradas. A ferramenta utilizada foi o Citespace, que permitiu realizar uma revisão bibliométrica sobre o tema, em 20 anos de publicação da Web of Science (1999/2019), cobrindo 187 publicações.

Depreende-se desta revisão que, mesmo com o crescimento exponencial do número de publicações acerca do tema Food Experience, o campo ainda se mostra em estágio embrionário, abordado por meio de pistas sobre a experiência sensorial e extrassensorial obtida com a prática de se alimentar, mas sem um aprofundamento sobre o construto em si, sua conceptualização, dimensões de pesquisa, antecedentes e consequentes. Novas pesquisas teórico-empíricas são necessárias para um maior delineamento do campo.

Acerca dos autores mais produtivos na base Web of Science, a maioria é especialista na área de turismo - o que dá sustentação ao fato de que grande parte das publicações sobre o assunto pertence ao campo do turismo. Cabe salientar que o referido campo obteve uma centralidade zero, provavelmente por fundamentar sua pesquisa buscando compreender o comportamento do turista em suas experiências gastronômicas — usando como aparato teórico autores da administração (Björk \& Kauppinen-Räisänenb, 2016; Peštek \& Činjarević, 2014; Sengel et al., 2015). Isso explica o porquê da análise sobre autores citados mais relevantes para 
Cardoso, L. O., Ferreira, F. L., Christino, J. M. M., \& Noronha, A. L. S. (2022, jan./abr.). Conhecendo o campo sobre food experience: uma revisão bibliométrica dos últimos 20 anos na base web of Science

o campo de Food Experience apontar uma predominância de especialistas ligados à administração e economia. A área de administração concentra a maior centralidade, apesar de possuir baixa frequência de publicações, o que indica uma área promissora de investigação.

Dentro do campo da Administração, merecem destaque as pesquisas ligadas à satisfação do consumidor, lealdade e intenção de retorno — bem como seus consequentes ao meio gastronômico - enquanto campo já consolidado. As palavras-chave de maior destaque são as relacionadas à experiência e satisfação do consumidor e à qualidade do serviço — fatores comprovados na literatura abordada (Kontukoski, Paakki, Thureson, Uimonen, \& Hopia, 2016; Jang \& Namkung, 2009; Adongo, Anuga, \& Dayour, 2015; Wu \& Liang, 2009; Sthapit, 2017; Sthapit, 2018; Yoon, Thompson, \& Parsa, 2009; Peng \& Cheng, 2015; Kim \& Jang, 2018). Os estudos tendem a focar em autenticidade, preferências, percepção do consumidor, intenção comportamental, emoção, escolha e comidas locais. Esses fatores são confirmados com os clusters encontrados, que se dividem em fatores que levam à satisfação do consumidor, atributos do estabelecimento e fatores intrínsecos que influenciam na escolha do estabelecimento.

Constata-se, porém, o campo sobre motivações e fatores que influenciam na tomada de decisão do consumidor, em uma visão mais micro e individualista, enquanto frutífero para novas pesquisas. Dando sustentação a essa afirmação, têm-se: (i) as palavras behavior e choice enquanto palavras-chave relevantes, mas ainda com poucas publicações; e (ii) a baixa quantidade de artigos pertencentes ao cluster que agrupou estudos sobre as motivações e tomada de decisão - e sua alta variedade e consequente baixa coesão nos assuntos pesquisados - que abrangem temas acerca do individualismo, necessidades sociais, atributos intrínsecos e extrínsecos, impacto, marca, consumo simbólico e status social.

Por fim, percebe-se uma grande importância dos estudos dos EUA, Inglaterra, China, Holanda e Nova Zelândia para as pesquisas, enquanto os estudos do Brasil indexados à base tratam sobre uma vertente psicológica e neurocientífica sobre a prática de comer e beber, mas não especificamente sobre Food Experience - o que mostra a importância de trazer essa abordagem para o país, frente a sua relevante atuação no mercado brasileiro nos últimos anos.

Uma das limitações foi o fato de ser utilizada no estudo apenas uma base de dados para a realização da revisão bibliométrica com o software CiteSpace - o programa permite também revisões bibliométricas utilizando a base SCOPUS. Sugere-se também que se faça uma revisão sistemática, que permitirá uma visão mais aprofundada sobre o tema e sanará algumas questões levantadas com o mapeamento bibliométrico, como: O que a literatura traz sobre o que é Food 
Cardoso, L. O., Ferreira, F. L., Christino, J. M. M., \& Noronha, A. L. S. (2022, jan./abr.). Conhecendo o campo sobre food experience: uma revisão bibliométrica dos últimos 20 anos na base web of Science

Experience? Quais são as principais conclusões sobre a tomada de decisão do consumidor de Food Experience? O que motiva o consumidor a frequentar restaurantes que adotam Food Experience? O que a literatura aponta enquanto gap para guiar futuras pesquisas sobre o tema? Ademais, acerca do campo de satisfação do consumidor enquanto campo já consolidado, poderse-á ser indicado o que já foi pesquisado, assim como os campos frutíferos para novos pesquisadores. Para a revisão sistemática, sugere-se, igualmente, que sejam consideradas outras bases de periódicos, como SCOPUS, Scielo, EBSCO, entre outras.

\section{Referências}

Adongo, C. A., Anuga, S. W., \& Dayour, F. (2015). Will they tell others to taste? International tourists' experience of Ghanaian cuisines. Tourism Management Perspectives, 15(2015), 57-64. https://doi.org/10.1016/j.tmp.2015.03.009

Björk, P., \& Kauppinen-Räisänen, H. (2016). Local food: a source for destination attraction. International Journal of Contemporary Hospitality Management, 28(1), 466-475. https://doi.org/10.1108/IJCHM-05-2014-0214

Björk, P., \& Kauppinen-Räisänen, H. (2019). Destination foodscape: A stage for travelers' Food Experience. Tourism Management, 71(2019), 466-475. https://doi.org/10.1016/j.tourman.2018.11.005

Chen, A., Peng, N., \& Hung, K. P. (2015). The effects of luxury restaurant environments on diners' emotions and loyalty. International Journal of Contemporary Hospitality Management, 27(2), 236-260. https://doi.org/10.1108/IJCHM-07-2013-0280

Chen, C., Song, I. Y., Yuan, X., \& Zhang, J. (2008). The thematic and citation landscape of data and knowledge engineering (1985-2007). Data \& Knowledge Engineering, 67(2), pp. 234-259. https://doi.org/10.1016/j.datak.2008.05.004

Diodato, V. P., \& Gellatly, P. (2013). Dictionary of Bibliometrics. Routledge.

Frank, R. A., \& Kalisewicz, S. (2000). Food experience and willingness to try novel foods. Appetite, 34(3), 335-335. https://doi.org/10.1006/appe.2000.0320

Gândara, J. M. G., Gimenes, M. H. S. G., \& Mascarenhas, R. G. (2009). Reflexões sobre o Turismo Gastronômico na perspectiva da sociedade dos sonhos. Netto, A. P., \& dos Reis Ansarah, M. G. (Eds.). Segmentação do mercado turístico: estudos, produtos e perspectivas (pp.179-191). Manole.

Globo. (2016) "Após sucesso em Paris e NY, moda de comer com olhos vendados chega ao Rio" Disponível em https://g1.globo.com/rio-de-janeiro/noticia/apos-sucesso-emparis-e-ny-moda-de-comer-com-olhos-vendados-chega-ao-rio.ghtml. Acesso em: 21 de julho de 2020. 
Cardoso, L. O., Ferreira, F. L., Christino, J. M. M., \& Noronha, A. L. S. (2022, jan./abr.). Conhecendo o campo sobre food experience: uma revisão bibliométrica dos últimos 20 anos na base web of Science

Goolaup, S., \& Mossberg, L. (2017). Exploring the concept of extraordinary related to food tourists' nature-based experience. Scandinavian Journal of Hospitality and Tourism, 17(1), 27-43. https://doi.org/10.1080/15022250.2016.1218150

Goolaup, S., Solér, C., \& Nunkoo, R. (2018). Developing a theory of surprise from travelers' extraordinary food experiences. Journal of Travel Research, 57(2), 218-231. https://doi.org/10.1177/0047287517691154

Gregorash, B. J. (2017). The modern Canadian restaurant: food for thought. Worldwide Hospitality and Tourism Themes, 9(4), 442-450. https://doi.org/10.1108/WHATT-042017-0016

Han, S. H., Nguyen, B., \& Simkin, L. (2016). The dynamic models of consumers' symbolic needs: in the context of restaurant brands. European Journal of Marketing, 50(7/8), 1348-1376. https://doi.org/10.1108/EJM-03-2015-0144

Hansen, K. V., Jensen, Ø., \& Gustafsson, I. B. (2005). The meal experiences of á la carte restaurant customers. Scandinavian Journal of Hospitality and Tourism, 5(2), 135151. https://doi.org/10.1080/15022250510014417

Hendijani, R. B. (2016). Effect of Food Experience on tourist satisfaction: the case of Indonesia. International Journal of Culture, Tourism and Hospitality Research, 10(3), 272-282. https://doi.org/10.1108/IJCTHR-04-2015-0030

Jang, S., \& Namkung, Y. (2009). Perceived quality, emotions, and behavioral intentions: Application of an extended Mehrabian-Russell model to restaurants. Journal of Business Research, 62(2009), 451-460. https://doi.org/10.1016/j.jbusres.2008.01.038

Jia, X., Dai, T., \& Guo, X. (2014). Comprehensive exploration of urban health by bibliometric analysis: 35 years and 11,299 articles. Scientometrics, 99(3), 881-894. https://doi.org/10.1007/s11192-013-1220-4

Jornal da Cidade. (2018). Gastronomia - Birosca s2. Disponível em http://degustatividade.com.br//wpcontent/uploads/2015/07/137a_ColunaGastronomia_Birosca S2.pdf. Acesso em: 21 de julho de 2020.

Kim, D., \& Jang, S. S. (2018). Online sharing behavior on social networking sites: Examining narcissism and gender effects. International Journal of Hospitality Management, 68(2018), 89-93. https://doi.org/10.1016/j.ijhm.2017.09.015

Kontukoski, M., Paakki, M., Thureson, J., Uimonen, H., \& Hopia, A. (2016). Imagined salad and steak restaurants: Consumers' colour, music and emotion associations with different dishes. International Journal of Gastronomy and Food Science, 4(2016), 111. https://doi.org/10.1016/j.ijgfs.2016.04.001

Kotler, P. (1973). Atmospherics as a marketing tool. Journal of Retailing, 49 (4), 48-64. Disponível em http://belzludovic.free.fr/nolwenn/Kotler\%20- 
Cardoso, L. O., Ferreira, F. L., Christino, J. M. M., \& Noronha, A. L. S. (2022, jan./abr.). Conhecendo o campo sobre food experience: uma revisão bibliométrica dos últimos 20 anos na base web of Science

\%20Atmospherics\%20as\%20a\%20marketing\%20tool\%20\%20(cit\%C3\%A9\%20171) \%20-\%201973.pdf. Acesso em: 21 de julho de 2020.

Li, X., Ma, E. \& Qu, H. (2017). Knowledge mapping of hospitality research- A visual analysis using CiteSpace. International Journal of Hospitality Management, 60(2017), 77-93. https://doi.org/10.1016/j.ijhm.2016.10.006

Longart, P., Wickens, E. \& Bakir, A. (2018). An investigation into restaurant attributes: A basis for a typology. International Journal of Hospitality \& Tourism Administration, 19(1), 95-123. https://doi.org/10.1080/15256480.2017.1305314

McNeill, L. \& Mather, D. (2016). Social involvement and consumption motivation: Cocreation of magic in the servicescape. Australasian Marketing Journal, 24(2016), 315-321. https://doi.org/10.1016/j.ausmj.2016.11.004

Mintz, S. W. (2001). Comida e antropologia: uma breve revisão. Revista Brasileira de Ciências Sociais, 16(47), 31-42. https://doi.org/10.1590/S0102-69092001000300002

Neff, M. \& Corley, E. (2009). 35 years and 160,000 articles: A bibliometric exploration of the evolution of ecology. Scientometrics, 80(3), 657-682. https://doi.org/ 10.1007/s11192008-2099-3

Peng, N. \& Chen, A. H. (2015). Diners' loyalty toward luxury restaurants: the moderating role of product knowledge. Marketing Intelligence \& Planning, 33(2), 179-196. https://doi.org/10.1108/MIP-03-2014-0049

Peštek, A. \& Činjarević, M. (2014). Tourist perceived image of local cuisine: the case of Bosnian food culture. British Food Journal, 116(11), 1821-1838. https://doi.org/10.1108/BFJ-01-2014-0046

Pu, B., Teah, M. \& Phau, I. (2019). Hot chili peppers, tears and sweat: how experiencing Sichuan cuisine will influence intention to visit city of origin. Sustainability, 11(13), 1-16. https://doi.org/10.3390/su11133561

Quan, S. \& Wang, N. (2004). Towards a structural model of the tourist experience: An illustration from Food Experiences in tourism. Tourism Management, 25(3), 297-305. https://doi.org/10.1016/S0261-5177(03)00130-4

Qiu, H. H. \& Liu, L. G. (2018). A study on the evolution of carbon capture and storage technology based on knowledge mapping. Energies, 11(5), 1-25. https://doi.org/10.3390/en11051103

Rodrigues, S. P., Van Eck, N. J., Waltman, L. \& Jansen, F. W. (2014). Mapping patient safety: a large-scale literature review using bibliometric visualisation techniques. $B M J$ Open, 4(3), 1-8. http://dx.doi.org/10.1136/bmjopen-2013-004468

Schifferstein, H. N. (2015). Employing consumer research for creating new and engaging Food Experiences in a changing world. Current Opinion in Food Science, 3(2015), 27-32. https://doi.org/10.1016/j.cofs.2014.11.004 
Cardoso, L. O., Ferreira, F. L., Christino, J. M. M., \& Noronha, A. L. S. (2022, jan./abr.). Conhecendo o campo sobre food experience: uma revisão bibliométrica dos últimos 20 anos na base web of Science

SEBRAE. (2018). Food Experience: Relatório do Sebrae mostra a importância de explorar cinco sentidos na gastronomia. Disponível em http://www.es.agenciasebrae.com.br/sites/asn/uf/ES/tendencia-food-experiencequando-a-experiencia-e-tao-importante-quanto-arefeicao,51be80b31e751610VgnVCM1000004c00210aRCRD. Acesso em: 21 de julho de 2020.

SEBRAE. (2017). Relatório de Inteligência - Food Experience. Disponível em http://www.es.agenciasebrae.com.br/asn/Estados/ES/Anexos/2017-0628_SebraeRJ_RI_Alimentos_Jun_FoodExp\%20(1).pdf. Acesso em: 21 de julho de 2020 .

Sengel, T., Karagoz, A., Cetin, G., Dincer, F. I., Ertugral, S. M. \& Bal1k, M. (2015). Tourists' approach to local food. Procedia-Social and Behavioral Sciences, 195(2015), 429437. https://doi.org/10.1016/j.sbspro.2015.06.485

Song, J. \& Qu, H. The mediating role of consumption emotions. (2017). International Journal of Hospitality Management, 66(2017), 66-76. https://doi.org/10.1016/j.ijhm.2017.06.015

Sthapit, E. (2017). Exploring tourists' memorable Food Experiences: A study of visitors to Santa's official hometown. Anatolia, 28(3), 404-421. https://doi.org/10.1080/13032917.2017.1328607

Sthapit, E. (2018). Is there more to the effects of tourists' local food consumption on postconsumption behaviour? Anatolia, 29(4), 614-616. https://doi.org/10.1080/13032917.2018.1517655

Teng C. \& Chang, J. Mechanism of customer value in restaurant consumption: Employee hospitality and entertainment cues as boundary conditions. (2013). International Journal of Hospitality Management, 32(2013), 169-178. https://doi.org/10.1016/j.ijhm.2012.05.008

US News \& World Report. (2020). Most Powerful Countries in the World. Disponível em < https://www.usnews.com/news/best-countries/power-rankings >. Acesso em: $11 \mathrm{de}$ fevereiro de 2021.

Van Nunen, K., Li, J., Reniers, G. \& Ponnet, K. (2018). Bibliometric analysis of safety culture research. Safety Science, 108(2018), 248-258.

https://doi.org/10.1016/j.ssci.2017.08.011

Van Raan, A. (2003). The use of bibliometric analysis in research performance assessment and monitoring of interdisciplinary scientific developments. TATuP-Zeitschrift für Technikfolgenabschätzung in Theorie und Praxis, 12(1), 20-29. https://doi.org/ 10.14512/tatup.12.1.20. 
Cardoso, L. O., Ferreira, F. L., Christino, J. M. M., \& Noronha, A. L. S. (2022, jan./abr.). Conhecendo o campo sobre food experience: uma revisão bibliométrica dos últimos 20 anos na base web of Science

Wang, S., Kirillova, K. \& Lehto, X. (2017). Travelers' Food Experience sharing on social network sites. Journal of Travel \& Tourism Marketing, 34(5), 680-693. https://doi.org/10.1080/10548408.2016.1224751

Wang, M. H., Yu, T. C. \& Ho, Y. S. (2010). A bibliometric analysis of the performance of Water Research. Scientometrics, 84(3), 813-820. https://doi.org/ 10.1007/s11192-0090112-0

Warde, A. (2018). Changing Tastes? The Evolution of Dining Out in England. Gastronomica, 18(4), 1-12. https://doi.org/10.1525/gfc.2018.18.4.1

Wu, C. H. J. \& Liang, R. D. (2009). Effect of experiential value on customer satisfaction with service encounters in luxury-hotel restaurants. International Journal of Hospitality Management, 28(4), 586-593. https://doi.org/10.1016/j.ijhm.2009.03.008

Xiang, C., Wang, Y. \& Liu, H. (2017). A scientometrics review on nonpoint source pollution research. Ecological Engineering, 99(2017), 400-408. https://doi.org/ 10.1016/j.ecoleng.2016.11.028

Yoon, H. J., Thompson, S. S. \& Parsa, H. G. (2009). Bayesian approach to assess consumers' brand selection process and identification of brand attributes in a service context. International Journal of Hospitality Management, 28(1), 33-41. https://doi.org/ 10.1016/j.ijhm.2008.03.003 